EUROPEAN CENTRAL BANK WORKING PAPER SERIES

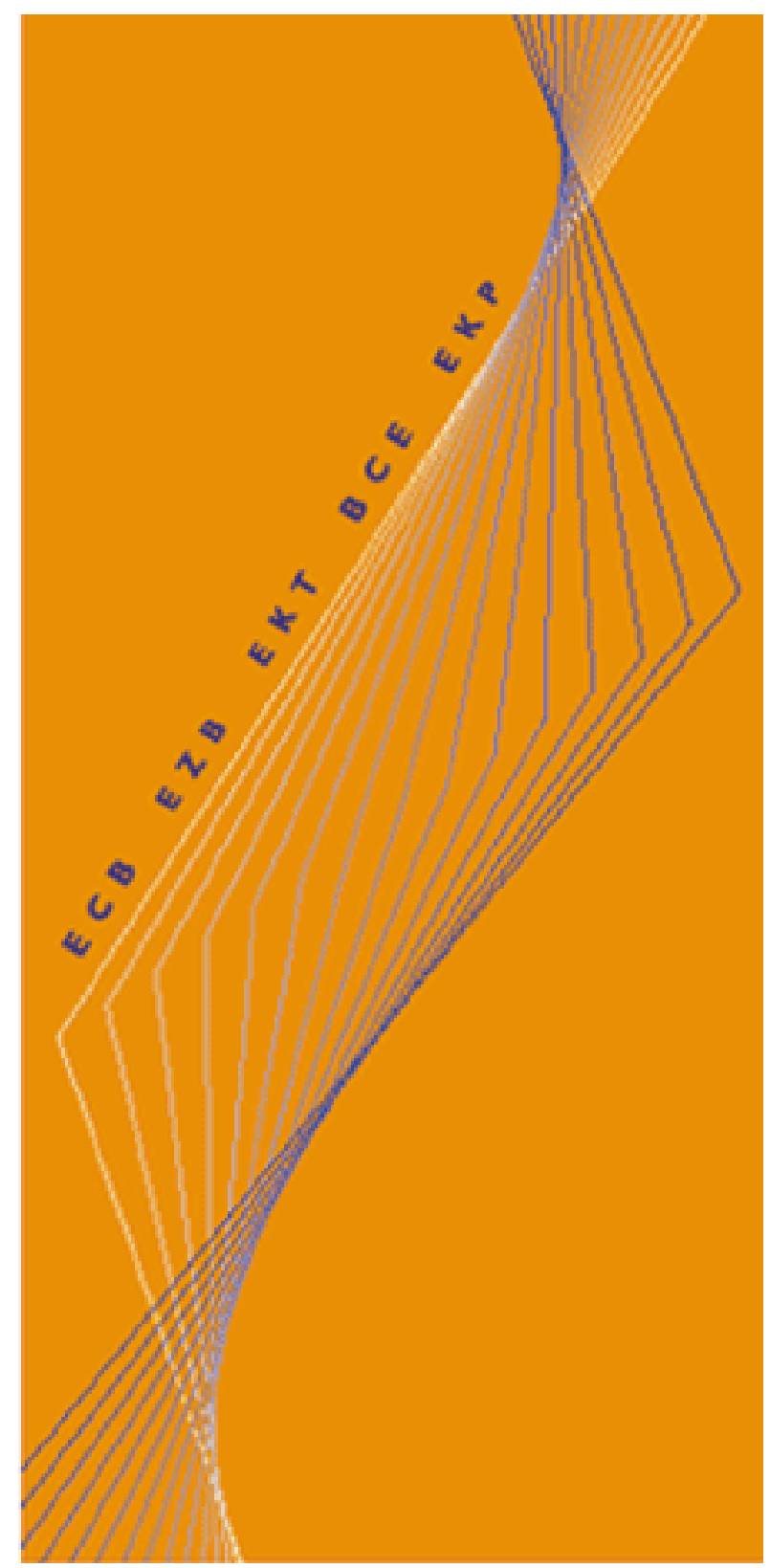

WORKING PAPER NO. 227

MONETARY POLICY IN A LOW PASS-THROUGH ENVIRONMENT

BY TOMMASO MONACELLI

April 2003 


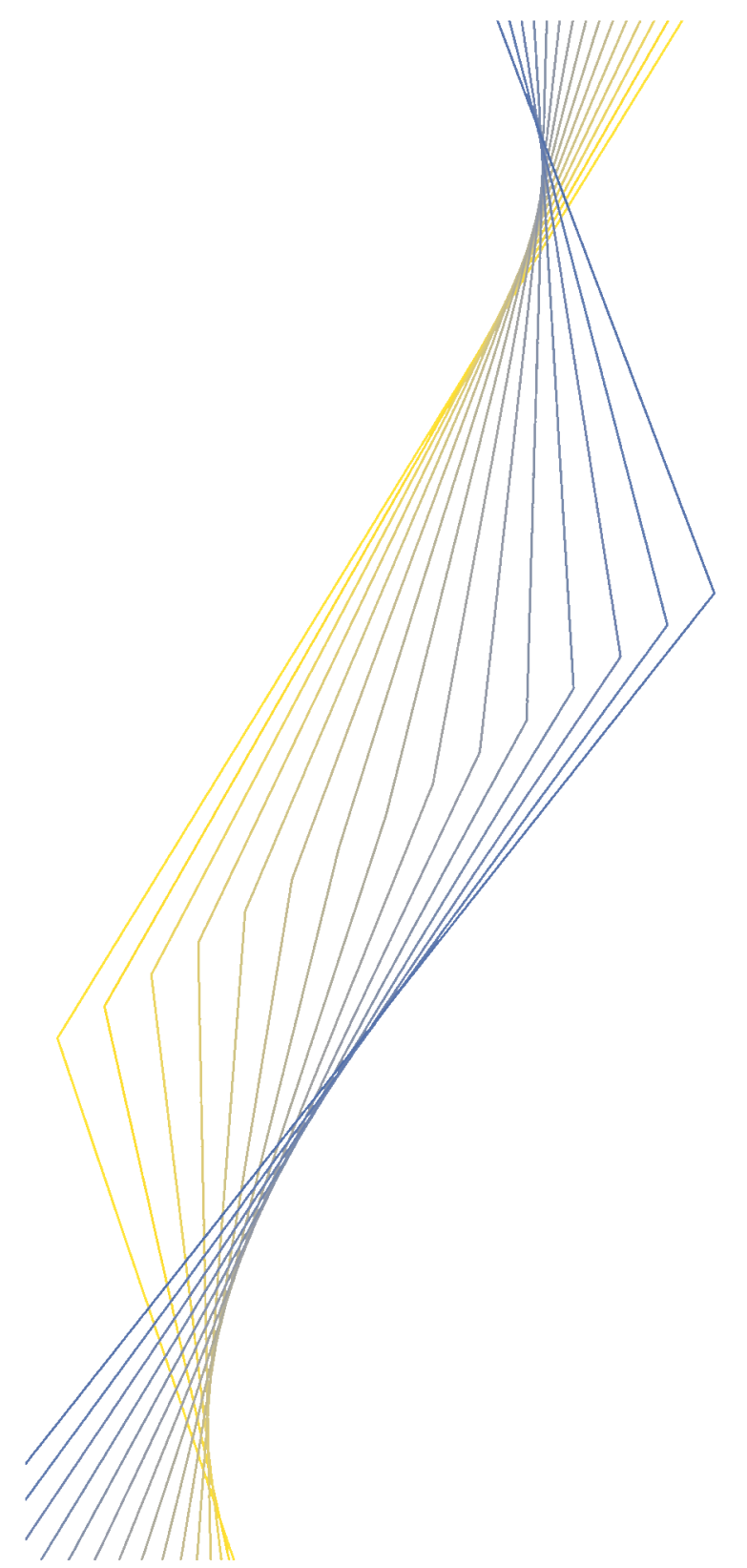

WORKING PAPER NO. 227

MONETARY POLICY IN A

LOW PASS-THROUGH

ENVIRONMENT'

BY TOMMASO MONACELLI'

\section{April 2003}

I First draft 2002. Part of this work was completed when I was Research Visitor at the DGR of the European Central Bank, whom I thank for a warm hospitality. I thank the Editorial Board of the ECB Working Paper Series and an anonymous referee for valuable comments. I also would like to thank Martin Uribe for useful discussions, and participants to seminars at the European Central Bank, the 2002 CEPR-ESSIM Conference, the Bank of Italy, and Catholic University of Milan for their comments. The opinions expressed herein are those of the authors and do not necessarily represent those of the European Central Bank. This paper can be downloaded without charge from http://www.ecb. int or from the Social Science Research Network electronic library at: http://ssrn.com/ abstract_id $=x x x x x$

2 IGIER, Universita' Bocconi, correspondence: IGIER Universita' Bocconi,Via Salasco 5, 20136 Milan, Italy. Email: tommaso.monacelli@uni-bocconi.it, web page: www.igier.uni-bocconi.it/monacelli. Tel: +39-02-5836-3330, fax: +39-02-5836-3302. 
(C) European Central Bank, 2003

$\begin{array}{ll}\text { Address } & \text { Kaiserstrasse 29 } \\ & \text { D-603 I I Frankfurt am Main } \\ & \text { Germany } \\ & \text { Postfach } 1603 \text { I9 } \\ \text { Postal address } & \text { Germany Frankfurt am Main } \\ & +4969 \text { I344 } 0 \\ \text { Telephone } & \text { http://www.ecb.int } \\ \text { Internet } & +4969 \text { I344 } 6000 \\ \text { Fax } & 4 I \mid \text { I44 ecb d } \\ \text { Telex } & \end{array}$

All rights reserved by the author/s.

Reproduction for educational and non-commercial purposes is permitted provided that the source is acknowledged. The views expressed in this paper do not necessarily reflect those of the European Central Bank.

ISSN I56I-08I0 (print)

ISSN I725-2806 (online) 


\section{Contents}

$\begin{array}{ll}\text { Abstract } & 4\end{array}$

Non-technical summary $\quad 5$

$\begin{array}{lll}\text { I Introduction } & 7\end{array}$

2 The model 9

2.I Domestic households 9

$\begin{array}{ll}2.2 \text { Domestic producers } & 12\end{array}$

2.3 Incomplete pass-through and imports pricing 13

$\begin{array}{lll}2.4 & \text { Goods market equilibrium } & 16\end{array}$

$\begin{array}{lll}2.5 & \text { Policy target in the rest of the world } & 17\end{array}$

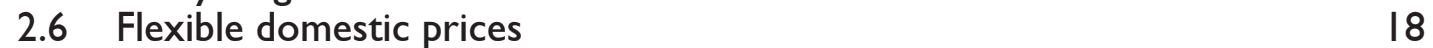

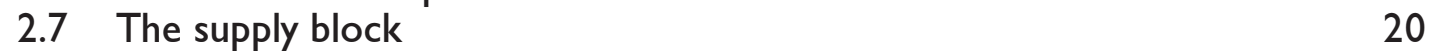

$\begin{array}{lll}2.8 & \text { The demand block } & 22\end{array}$

2.9 Breaking the canonical representation 23

3 Policy trade-offs in the small economy 24

4 Optimal monetary policy design 25

4.I Time consistent policy 26

$\begin{array}{ll}4.2 & \text { Optimal plan } \\ & 29\end{array}$

$5 \quad$ Dynamics under the optimal policy 29

6 Simple policy rules 31

7 Conclusions $\quad 32$

$\begin{array}{lll}\text { A Derivation of equation (36) } & 34\end{array}$

B Deriving the optimal plan 35

$\begin{array}{ll}\text { References } & 37\end{array}$

$\begin{array}{ll}\text { Table and figures } & 40\end{array}$

European Central Bank working paper series 43

ECB • Working Paper No 227• April $2003 \quad 3$ 


\begin{abstract}
We study the effects on the optimal monetary policy design problem of allowing for deviations from the law of one price in import goods prices. We reach three basic results. First, incomplete pass-through renders the analysis of monetary policy of an open economy fundamentally different from the one of a closed economy, unlike canonical models with perfect pass-through which emphasize a type of isomorphism. Second, and in response to efficient productivity shocks, incomplete pass-through has the effect of generating endogenously a short-run tradeoff between the stabilization of inflation and of the output gap. Third, in studying the optimal program under commitment relative to discretion, we show that the former entails a smoothing of the deviations from the law of one price, in stark contrast with the established empirical evidence. In addition, an optimal commitment policy always requires, relative to discretion, more stable nominal and real exchange rates.
\end{abstract}

Keywords: deviations from the law of one price, policy trade-off, gains from commitment, exchange rate channel.

JEL Classification Number: E52, E32, F41 


\section{Non-technical Summary}

This paper studies the effects on the optimal monetary policy design problem of allowing for deviations from the law of one price in import goods prices. Recently we have witnessed a growing interest in macroeconomics for the development of smallscale models applied to the analysis of monetary policy. The so-called NewKeynesian synthesis, exemplified by the work of Clarida, Gali and Gertler (1999) and Woodford (2002), bears the attractive feature of preserving tractability within the rigor of a dynamic optimizing general equilibrium setup.

The goal of a realistic representation of how in practice monetary policy is conducted in open economies has motivated the work of Benigno and Benigno (2002), Gali and Monacelli (2002), McCallum and Nelson (2001), Clarida, Gali and Gertler (2001), Ghironi (2000). Yet a limitation shared by all these models is the assumption that the pass-through of exchange rates to (import) prices is complete. This lies in stark contrast with the well-established empirical evidence that deviations from the law of one price for traded goods prices are large and pervasive.

This paper argues that allowing for incomplete pass-through bears important implications for the design of the optimal monetary policy problem.

First, incomplete pass-through alters the form of the canonical small-scale sticky-price model that has become the hallmark of the recent literature on the analysis of monetary policy. This framework typically reduces to a tractable two-equation dynamical system for inflation and output gap, consisting of a new Keynesian Phillips curve and of a dynamic IS-type equation. The paper shows that, unlike Clarida, Gali and Gertler (2001) who argue that the closed and the open economy version of the "canonical model" can be considered isomorphic to one another, the introduction of incomplete pass-through renders the analysis of monetary policy of an open economy fundamentally different from the one of a closed economy.

Second, allowing for deviations from the law of one price has the effect of generating endogenously a short-run trade-off between the stabilization of inflation and of the output gap. This has two consequences. On the one hand it renders the problem of optimal monetary policy non-trivial as well as realistic. On the other it marks a distinction from some of the recent literature (based on the prototype Calvo stickyprice model with perfect pass-through) that, in order to generate a meaningful policy trade-off, has typically resorted to ad-hoc (inefficient) cost-push shocks as exogenous shifters of the Phillips curve (Clarida et al, 1999, 2001). In our framework with incomplete pass-through a trade-off between policy objectives emerges in response to efficient productivity shocks and, furthermore, independently of the measure of inflation (CPI or producer price) featured in the loss criterion adopted by the Central Bank.

Third, the presence of such a real policy trade-off allows, within a fully forwardlooking setup, to contrast the features of the optimal policy program under commitment to the one under discretion. As emphasized by Woodford (2002) there is 
a fundamental reason why a discretionary behavior results in suboptimal outcomes in forward-looking models. Namely that discretion does not allow to design an efficient response to unexpected temporary shocks. This generates a source of gains from commitment which differs from the one outlined in the traditional analysis and related to the presence of an average inflation bias (see e.g., Kydland and Prescott 1977). More importantly, the study of this dimension of monetary policy is unfeasible within a large class of NOEM models that assumes one-period predetermined prices (or wages). For such an assumption typically gives rise to a Lucas-type aggregate supply curve in which the forward-looking nature of inflation is neglected, and along with it the channel through which the anticipation of future policy conduct comes to play a role. In our setting, to the contrary, a critical channel to the optimal commitment policy (relative to discretion) is the possibility, through the exchange rate (which is a forward-looking variable), to affect the expected future path of the deviations from the law of one price, and in turn the equilibrium path of inflation and output gap. A key contribution is to show that the optimal program, relative to the case with discretion, entails a partial, though not a complete, stabilization of the deviations from the law of one price. This is suggestive of a puzzle in the light of the established empirical evidence that deviations from the law of one price are rather large and persistent. 


\section{Introduction}

Recently we have witnessed a growing interest in macroeconomics for the development of small-scale models applied to the analysis of monetary policy. The so-called NewKeynesian synthesis, exemplified by the work of Clarida, Gali and Gertler (1999) and Woodford (2002), bears the attractive feature of preserving tractability within the rigor of a dynamic optimizing general equilibrium setup. This has provided an ideal ground for the study of the optimal conduct of monetary policy, the design and implementation of simple interest rate rules, and for a direct exploration of the data. Surprisingly much less attention has been devoted to the development of a similar paradigm in an open economy context. Several recent contributions within the so-called New Open Economy Macroeconomics (NOEM) literature have taken the form of elegant but highly stylized models in which the analysis of monetary policy is often still confined to inspecting the effects of money supply shocks. ${ }^{1}$ The goal of a realistic representation of how in practice monetary policy is conducted in open economies has motivated the work of Benigno and Benigno (2002), Gali and Monacelli (2002), McCallum and Nelson (2001), Clarida, Gali and Gertler (2001), Ghironi (2000). Yet a limitation shared by all these models is the assumption that the pass-through of exchange rates to (import) prices is complete. This lies in stark contrast with the well-established empirical evidence that deviations from the law of one price for traded goods prices are large and pervasive. ${ }^{2}$

The goal of this paper is to emphasize that allowing for incomplete pass-through bears important implications for the design of the optimal monetary policy problem. First, incomplete pass-through alters the form of the canonical small-scale stickyprice model that has become the hallmark of the recent literature on the analysis of monetary policy. This framework typically reduces to a tractable two-equation dynamical system for inflation and output gap, consisting of a new Keynesian Phillips curve and of a dynamic IS-type equation. Our first contribution is to show that, unlike Clarida, Gali and Gertler (2001) who argue that the closed and the open economy version of the "canonical model" can be considered isomorphic to one another, the

\footnotetext{
${ }^{1}$ As of now this literature is extremely rich. See Lane (2000) for a survey and contributions listed under Bryan Doyle's New Open Economy Macroeconomics Homepage at http://www.geocities.com/brian_m_doyle/open.html

${ }^{2}$ See Rogoff (1996) and Goldberg and Knetter (1997) for extensive theoretical and empirical surveys. The work by Engel (1993, 1999, 2002), Rogers and Jenkins (1995) strongly documents deviations from the law of one price also for consumer prices at a high level of disaggregation.
} 
introduction of incomplete pass-through renders the analysis of monetary policy of an open economy fundamentally different from the one of a closed economy.

Second, allowing for deviations from the law of one price has the effect of generating endogenously a short-run trade-off between the stabilization of inflation and of the output gap. This has two consequences. On the one hand it renders the problem of optimal monetary policy non-trivial as well as realistic. On the other it marks a distinction from some of the recent literature (based on the prototype Calvo stickyprice model with perfect pass-through) that, in order to generate a meaningful policy trade-off, has typically resorted to ad-hoc (inefficient) cost-push shocks as exogenous shifters of the Phillips curve (Clarida et al, 1999, 2001). In our framework with incomplete pass-through a trade-off between policy objectives emerges in response to efficient productivity shocks and, furthermore, independently of the measure of inflation (CPI or producer price) featured in the loss criterion adopted by the Central Bank.

Third, the presence of such a real policy trade-off allows, within a fully forwardlooking setup, to contrast the features of the optimal policy program under commitment to the one under discretion. As emphasized by Woodford (2002) there is a fundamental reason why a discretionary behavior results in suboptimal outcomes in forward-looking models. Namely that discretion does not allow to design an efficient response to unexpected temporary shocks. This generates a source of gains from commitment which differs from the one outlined in the traditional analysis and related to the presence of an average inflation bias (see e.g., Kydland and Prescott 1977). More importantly, the study of this dimension of monetary policy is unfeasible within a large class of NOEM models that assumes one-period predetermined prices (or wages). ${ }^{3}$ For such an assumption typically gives rise to a Lucas-type aggregate supply curve in which the forward-looking nature of inflation is neglected, and along with it the channel through which the anticipation of future policy conduct comes to play a role. In our setting, to the contrary, a critical channel to the optimal commitment policy (relative to discretion) is the possibility, through the exchange rate (which is a forward-looking variable), to affect the expected future path of the deviations from the law of one price, and in turn the equilibrium path of inflation and output gap. A key contribution is to show that the optimal program, relative to the case with discretion, entails a partial, though not a complete, stabilization of the deviations from the law of one price. This is suggestive of a puzzle in the light of the

\footnotetext{
${ }^{3}$ See, e.g, Obstfeld and Rogoff (1995), Corsetti and Pesenti (2002), Sutherland(2002).
} 
established empirical evidence that deviations from the law of one price are rather large and persistent.

Turning to the recent literature, Devereux and Engle (2002b), Corsetti and Pesenti (2002) and Sutherland (2002) also study the impact of incomplete pass-through on the optimal conduct of monetary policy. Their framework differs from the one of the present paper for it features one-period predetermined prices and hence does not lend it self to the analysis of the dynamic gains from commitment undertaken here. ${ }^{4}$ Adolfson (2002) and Smets and Wouters (2002) are contributions more in line with the present paper. They differ in three dimensions. First, their setting cannot be reduced to a tractable compact form easily comparable to the small-scale canonical sticky-price model previously adopted by the literature. Second, they focus only on the optimal policy under discretion, and hence neglect the crucial role played under commitment by the expectational channel of the exchange rate to inflation. This is a critical dimension of the monetary policy problem explored in detail in this paper. Third, they do not focus on the comparison of alternative policy rules.

The rest of the paper is organized as follows. Section 2 presents a model of the world economy in which two asymmetric countries, a small open economy and a large approximately closed one, coexist. Section 3 analyzes the basic trade-offs implied by the introduction of incomplete pass-through, while Section 4 discusses the details of the optimal monetary policy program. Section 5 compares the performance of alternative simple rules for monetary policy. Section 6 concludes.

\section{The Model}

\subsection{Domestic Households}

The domestic economy is populated by infinitely-lived households, consuming DixitStiglitz aggregates of domestic $\left(C_{H}\right)$ and imported $\left(C_{F}\right)$ goods, by domestic firms producing a differentiated good, and by a continuum of importing firms that operate as price setters in the local market. All goods are tradeable. In the following, lower case letters indicate log deviations from respective steady-state values while capital letters indicate levels. Let's define $C$ as a composite consumption index:

$$
C_{t} \equiv\left[(1-\gamma)^{\frac{1}{\eta}} C_{H, t} \frac{\eta-1}{\eta}+\gamma^{\frac{1}{\eta}} C_{F, t}^{\frac{\eta-1}{\eta}}\right]^{\frac{\eta}{\eta-1}}
$$

\footnotetext{
${ }^{4}$ Furthermore Burstein, Eichenbaum and Rebelo (2002) obtain incomplete pass-through as a consequence of the presence of distribution costs.
} 
with $C_{H}$ and $C_{F}$ being indexes of consumption of domestic and foreign goods respectively. ${ }^{5}$ Notice that under this specification $\eta$ measures the elasticity of substitution between domestic and foreign goods. The optimal allocation of expenditures between domestic and foreign goods implies:

$$
C_{H, t}=(1-\gamma)\left(\frac{P_{H, t}}{P_{t}}\right)^{-\eta} C_{t} \quad ; \quad C_{F, t}=\gamma\left(\frac{P_{F, t}}{P_{t}}\right)^{-\eta} C_{t}
$$

where $P_{t} \equiv\left[(1-\gamma) P_{H, t}^{1-\eta}+\gamma P_{F, t}^{1-\eta}\right]^{\frac{1}{1-\eta}}$ is the consumer price index (CPI).

We assume the existence of complete markets for state-contingent money claims expressed in units of domestic currency. Under this assumption the first order conditions of the consumer's problem are standard and can be written in a convenient log-linearized form as:

$$
\begin{gathered}
w_{t}-p_{t}=\sigma c_{t}+\varphi n_{t} \\
c_{t}=E_{t}\left\{c_{t+1}\right\}-\frac{1}{\sigma}\left(r_{t}-E_{t}\left\{\pi_{t+1}\right\}\right)
\end{gathered}
$$

where $w_{t}$ is the nominal wage, $n_{t}$ is labor hours, $r_{t}$ is the log nominal interest rate, and $\pi_{t}$ is the CPI inflation rate. ${ }^{6}$

In the rest of the world a representative household faces a problem identical to the one outlined above. Hence a set of analogous optimality conditions characterize the solution to the consumer's problem in the world economy. As in Gali and Monacelli (2002), however, the size of the small open economy is negligible relative to the rest of the world, an assumption that allows to treat the latter as if it was a closed economy. ${ }^{7}$

\footnotetext{
${ }^{5}$ Such indexes are in turn given by CES aggregators of the quantities consumed of each type of good. The optimal allocation of any given expenditure within each category of goods yields the demand functions:

$$
C_{H, t}(i)=\left(\frac{P_{H, t}(i)}{P_{H, t}}\right)^{-\varepsilon} C_{H, t} \quad ; \quad C_{F, t}(i)=\left(\frac{P_{F, t}(i)}{P_{F, t}}\right)^{-\varepsilon} C_{F, t}
$$

for all $i \in[0,1]$, where $P_{H, t} \equiv\left(\int_{0}^{1} P_{H, t}(i)^{1-\varepsilon} d i\right)^{\frac{1}{1-\varepsilon}}$ and $P_{F, t} \equiv\left(\int_{0}^{1} P_{F, t}(i)^{1-\varepsilon} d i\right)^{\frac{1}{1-\varepsilon}}$ are the price indexes for domestic and imported goods respectively, both expressed in home currency. The elasticity of substitution between goods within each category is given by $\varepsilon>1$.

${ }^{6}$ This follows from maximizing a separable utility function of the form $\frac{1}{1-\sigma} C_{t}^{1-\sigma}-\frac{1}{1+\varphi} N_{t}^{1+\varphi}$ under a standard sequence of budget constraints. Hence $\sigma$ denotes the inverse of the intertermporal elasticity of consumption and $\varphi$ the inverse of the elasticty of labor supply.

${ }^{7}$ Notice that, more precisely, this is a world of two asymmetric countries in which one is small relative to the other (whose equilibrium is in the limit taken as exogenous). This kind of setup allows to model explicitly the role of financial markets and risk sharing and to overcome a typical problem of unit-root in consumption that characterizes traditional small open economy models with
} 


\subsubsection{Pass-through, the Real Exchange Rate, and Deviations from PPP}

Log-linearization of the CPI expression around a steady-state yields:

$$
p_{t}=(1-\gamma) p_{H, t}+\gamma p_{F, t}
$$

Domestic producer inflation (defined as the rate of change in the index of domestic goods prices), and CPI-inflation are linked according to

$$
\begin{aligned}
\pi_{t} & =(1-\gamma) \pi_{H, t}+\gamma \pi_{F, t} \\
& =\pi_{H, t}+\gamma \Delta s_{t}
\end{aligned}
$$

where

$$
s_{t} \equiv p_{F, t}-p_{H, t}
$$

denotes the (log) terms of trade, i.e., the domestic currency relative price of imports. Notice that the equation above holds independently of the degree of pass-through. The change in this price can be written in terms of relative inflation rates as:

$$
\Delta s_{t}=\pi_{F, t}-\pi_{H, t}
$$

The treatment of the rest of the world as an (approximately) closed economy (with goods produced in the small economy representing a negligible fraction of the world's consumption basket) implies that $p_{t}^{*}=p_{F, t}^{*}$, and $\pi_{t}^{*}=\pi_{F, t}^{*}$, for all $t$, i.e., an equivalence between domestic and CPI inflation holds in the world economy.

Under incomplete pass-through the law of one price does not hold. This has implications for the relationship between the real exchange rate and the terms of trade. Let's define $e_{t} \equiv \log \mathcal{E}_{t}$ as the (log) nominal exchange rate (i.e., the domestic currency price of one unit of foreign currency). In particular, by using equation (5), one can write:

$$
\begin{aligned}
q_{t} & =e_{t}+p_{t}^{*}-p_{t} \\
& =\left(e_{t}+p_{t}^{*}-p_{F, t}\right)+(1-\gamma) s_{t} \\
& =\psi_{F, t}+(1-\gamma) s_{t}
\end{aligned}
$$

incomplete markets. See Schmitt-Grohe and Uribe (2002) for a discussion on how to "close small open economy models". 
where

$$
\psi_{F, t} \equiv\left(e_{t}+p_{t}^{*}\right)-p_{F, t}
$$

denotes the deviation of the world price from the domestic currency price of imports, a measure of the deviations from the law of one price. In what follows we will define this measure as the law-of-one price gap (l.o.p gap henceforth).

Equation (9) deserves some comments. It stands clear that two are the sources of deviation from aggregate PPP in this framework. The first one is due to the heterogeneity of consumption baskets between the small economy and the rest of the world, an effect captured by the term $(1-\gamma) s_{t}$, as long as $\gamma<1$. For $\gamma \rightarrow 1$, in fact, the two aggregate consumption baskets coincide and relative price variations are not required in equilibrium. This will become more clear below when I illustrate risk sharing. The second source of deviation from PPP is due to the deviation from the law of one price, captured by movements in $\psi_{F, t}$. With incomplete pass-through the l.o.p gap contributes to the volatility of the real exchange rate. It will stand clear later that the term $\psi_{F, t}$ plays a key role in determining the dynamics of imports inflation.

\subsection{Domestic Producers}

In the market of the domestic goods, there is a continuum of monopolistic competitive firms (owned by consumers), indexed by $i \in[0,1]$. They operate a CRS technology: $Y_{t}(i)=Z_{t} N_{t}(i)$, where $Z$ is a total factor productivity shifter. Cost minimization typically leads to the following efficiency condition for the choice of labor input :

$$
m c_{t}=\left(w_{t}-p_{H, t}\right)-z_{t}
$$

where $m c$ indicates the real marginal cost which is common across producers. In the following, domestic (log) productivity is assumed to follow a simple stochastic autoregressive process:

$$
z_{t}=\rho z_{t-1} \xi_{z, t}
$$

where $0 \leq \rho \leq 1$ is a persistence parameter and $\xi_{z, t}$ is an i.i.d shock.

Domestic firms are allowed to reset their price according to a standard Calvo-Yun rule, which implies receiving a price signal at a constant random rate $\theta_{H}$. Let then $\theta_{H}^{k}$ be the probability that the price set at time $t$ will still hold at time $t+k$. Firm $i$ faces 
domestic and foreign demand. For simplicity we assume that the export price of the domestic good, $P_{H}^{*}(i)$, is flexible and determined by the law of one price. This kind of pricing technology leads typically to the following log-linear equation for equilibrium newly set prices:

$$
p_{H, t}^{n e w}=\left(1-\beta \theta_{H}\right) E_{t}\left\{\sum_{k=0}^{\infty}\left(\beta \theta_{H}\right)^{k}\left(m c_{t+k}+p_{H, t+k}\right)\right\}
$$

The domestic aggregate price index evolves according to:

$$
P_{H, t}=\left[\theta_{H}\left(P_{H, t-1}\right)^{1-\varepsilon}+\left(1-\theta_{H}\right)\left(P_{H, t}^{n e w}\right)^{1-\varepsilon}\right]^{\frac{1}{1-\varepsilon}}
$$

By log-linearizing (14) and combining with (13) one can derive a typical forwardlooking Phillips curve:

$$
\pi_{H, t}=\beta E_{t} \pi_{H, t+1}+\lambda_{H} m c_{t}
$$

where $\lambda_{H} \equiv\left(\frac{\left(1-\theta_{H}\right)\left(1-\beta \theta_{H}\right)}{\theta_{H}}\right)$. An aggregate supply relation of this kind has become a basic ingredient of recent optimizing models of the so-called New Keynesian Synthesis. $^{8}$

\subsection{Incomplete Pass-Through and Imports Pricing}

We now turn to discuss the dynamic of import pricing, which is the central modelling novelty of the paper. In recent work Campa and Goldberg (2002) estimate import pass-through elasticities for a range of OECD countries. They find that the degree of pass-through is partial in the short-run and that it becomes gradually complete only in the long-run. Their results imply a rejection of both the extreme assumptions on import pricing that characterize a wide array of papers in the NOEM literature: local vs. producer currency pricing. ${ }^{9}$ According to the first view domestic currency prices of imports are totally unresponsive to exchange rate movements in the short run, while the opposite is true in the latter case. What this evidence suggests is that a setup featuring incomplete exchange rate pass-through should allow the deviations from the law of one price to be, as well as large, gradual and persistent.

\footnotetext{
${ }^{8}$ See Woodford (1999a), Clarida, Gali and Gertler (2000).

${ }^{9}$ The original Obstfeld and Rogoff (1995) paper assumes PCP, while in the LCP category fall, among many others, papers by Betts and Devereux (2000), Chari, Kehoe and McGrattan (2002), Devereux and Engel (2001).
} 
In this section we develop the model in the direction of accounting for these facts. We assume that the domestic market is populated by local retailers who import differentiated goods for which the law of one price holds "at the dock". In setting the domestic currency price of these goods the importers solve an optimal (dynamic) markup problem. This generates deviations from the law of one price in the short run, while complete pass-through is reached only asymptotically, implying a long-run holding of the law of one price. This feature is more in line with the empirical patterns described above and critically distinguishes our modelling of incomplete pass-through from the one of other recent papers (see e.g., Corsetti and Pesenti, 2002).

Consider a local retailer importing good $j$ at a cost (i.e., price paid in the world market) $\mathcal{E}_{t} P_{F, t}^{*}(j)$, where $\mathcal{E}$ is the level of the nominal exchange rate. Like the local producers, the same retailer faces a downward sloping demand for such good and therefore chooses a price $P_{F, t}(j)$, expressed in units of domestic currency, to maximize:

$$
\begin{gathered}
E_{t}\left\{\sum_{k=0}^{\infty} \beta^{k} \Lambda_{t, t+k} \theta_{F}^{k}\left(P_{F, t}(j)-\mathcal{E}_{t+k} P_{F, t+k}^{*}(j)\right) C_{F, t+k}(j)\right\} \\
\text { s.t } C_{F, t}(j)=\left(\frac{P_{F, t}(j)}{P_{F, t}}\right)^{-\varepsilon} C_{F, t}
\end{gathered}
$$

where $P_{F, t}^{*}(j)$ is the foreign-currency price of the imported good, $\theta_{F}^{k}$ is the probability that the price $P_{F, t}(j)$ set for good $j$ at time $t$ still holds $k$ periods ahead, and $\beta^{k} \Lambda_{t, t+k}$ is a relevant stochastic discount factor. In general, the degree of stickiness in the adjustment of domestic prices $\theta_{H}$ is allowed to differ from the one of import prices expressed in local currency $\theta_{F}$.

The FOC of this problem yields:

$$
P_{F, t}^{n e w}(j)=\left(\frac{\varepsilon}{\varepsilon-1}\right) \frac{E_{t}\left\{\sum_{k=0}^{\infty} \beta^{k} \Lambda_{t, t+k} \theta_{F}^{k}\left(\mathcal{E}_{t+k} P_{F, t+k}^{*} C_{F, t+k}(j)\right)\right\}}{E_{t}\left\{\sum_{k=0}^{\infty} \beta^{k} \Lambda_{t, t+k} \theta_{F}^{k} C_{F, t+k}(j)\right\}}
$$

The log-linear aggregate imports price evolves according to:

$$
p_{F, t}=\theta_{F} p_{F, t-1}+\left(1-\theta_{F}\right) p_{F, t}^{n e w}
$$

The log-linear version of (16) yields:

$$
p_{F, t}^{n e w}=\left(1-\beta \theta_{F}\right) E_{t} \sum_{k=0}^{\infty}\left(\beta \theta_{F}\right)^{k}\left(\psi_{F, t}+p_{F, t+k}\right)
$$


By combining (17) with (18), one can obtain an aggregate supply curve for imports goods:

$$
\pi_{F, t}=\beta E_{t} \pi_{F, t+1}+\lambda_{F} \psi_{F, t}
$$

where $\lambda_{F} \equiv \frac{\left(1-\theta_{F}\right)\left(1-\beta \theta_{F}\right)}{\theta_{F}}$. Therefore import price inflation rises as the world price of imports exceeds the local currency price of the same good. In other words, a nominal depreciation determines a wedge between the price paid by the importers in the world market and the local currency price applied in the domestic market. This wedge acts as an increase in her real marginal cost and therefore increases foreign goods inflation. The parameter $\theta_{F}$ governs the degree of pass-through. ${ }^{10}$ Notice that in the case $\theta_{F}=0$ equation (18) reduces to a simple law-of-one price equation $p_{F, t}=e_{t}+p_{t}^{*}$. Notice also that equation (19) can be written, integrating forward, as

$$
\pi_{F, t}=E_{t}\left\{\sum_{k=0}^{\infty} \beta^{k} \lambda_{F} \psi_{F, t+k}\right\}
$$

which shows that imports price inflation is a purely forward-looking variable, for its current behavior depends on the current and expected future deviations from the law of one price.

\subsubsection{Risk Sharing and Uncovered Interest Parity}

The existence of complete markets for nominal state contingent securities has implications for consumption risk sharing. Formally movements in the ratio of the marginal utilities of consumption must imply, in equilibrium, movements in the real exchange rate. This typically implies a log-linearized condition $^{11}$ :

$$
c_{t}=c_{t}^{*}+\frac{1}{\sigma} q_{t}
$$

which can be rewritten as

$$
c_{t}=c_{t}^{*}+\frac{1}{\sigma}\left((1-\gamma) s_{t}+\psi_{F, t}\right)
$$

\footnotetext{
${ }^{10}$ In fact the textbook definition of exchange rate pass-through is the percentage change in the local currency import price resulting from a one percent change in the exchange rate betwen importing and exporting country (see Goldberg and Knetter, 1997).

${ }^{11}$ See Chari, Kehoe and McGrattan (2002), Gali and Monacelli (2002) for a formal derivation of this condition.
} 
where $\sigma$ is the intertemporal elasticity of substitution in consumption. Hence deviations from the law of one price, by affecting the movements of the real exchange rate, affect the movements of the relative consumption baskets as well.

Under complete international asset markets it also possible to derive a standard log-linear version of an uncovered interest parity condition

$$
r_{t}-r_{t}^{*}=E_{t}\left\{\Delta e_{t+1}\right\}
$$

It is easy to show that such an equation results from combining efficiency conditions for an optimal portfolio of bonds by both domestic and foreign residents.

\subsubsection{Decomposition of the Real Marginal Cost}

By combining (4), (11) and (22) one obtains, after aggregation, an equilibrium equation for the domestic real marginal cost (or inverse of the domestic markup), which also expresses the equilibrium in the labor market:

$$
\begin{aligned}
m c_{t} & =\left(w_{t}-p_{H, t}\right)-z_{t} \\
& =\left(w_{t}-p_{t}\right)+\gamma s_{t}-z_{t} \\
& =\sigma c_{t}+\varphi y_{t}+\gamma s_{t}-(1+\varphi) z_{t} \\
& =\varphi y_{t}-(1+\varphi) z_{t}+\sigma y_{t}^{*}+s_{t}+\psi_{F, t}
\end{aligned}
$$

Equation (24) shows that the domestic real marginal cost is increasing in domestic output (through its effect on employment and therefore the real wage) and decreasing in domestic technology (through its direct effect on labor productivity). However, open economy factors as well affect the real marginal cost: world output (through its effect on labor supply via risk sharing) and a "relative price effect" captured by $s_{t}$ and $\psi_{F, t}$.

\subsection{Goods Market Equilibrium}

To describe the equilibrium in the domestic goods market it is first useful to consider

log-linearized versions of the isoelastic demand functions. In particular local and foreign demand for domestic goods can be written respectively:

$$
\begin{aligned}
c_{H, t} & =-\eta\left(p_{H, t}-p_{t}\right)+c_{t} \\
& =\eta \gamma s_{t}+c_{t}
\end{aligned}
$$




$$
\begin{aligned}
c_{H, t}^{*} & =-\eta\left(p_{H, t}^{*}-p_{t}^{*}\right)+c_{t}^{*} \\
& =\eta\left(\left(p_{F, t}+\psi_{F, t}\right)-p_{H, t}\right)+c_{t}^{*} \\
& =\eta\left(s_{t}+\psi_{F, t}\right)+c_{t}^{*}
\end{aligned}
$$

Hence foreign demand for domestic goods (i.e., exports) rises both when the terms of trade depreciate (i.e., the price $p_{H}$ falls relative to $p_{F}$ ) and when the domestic currency price of foreign goods $p_{F}$ falls relative to the world price (i.e., $\psi_{F}$ rises).

Finally, the demand for imports will read

$$
\begin{aligned}
c_{F, t} & =-\eta\left(p_{F, t}-p_{t}\right)+c_{t} \\
& =-\eta(1-\gamma) s_{t}+c_{t}
\end{aligned}
$$

Goods market clearing implies $y_{t}(i)=(1-\gamma) c_{H, t}(i)+\gamma c_{H, t}^{*}(i)$ for all goods $i$. After aggregating, substituting the above demand functions and rearranging the by using (22) one obtains a simple proportionality relation between domestic and foreign output which is as well affected by the existence of incomplete pass-through:

$$
y_{t}-y_{t}^{*}=\frac{1}{\sigma}\left[\omega_{s} s_{t}+\omega_{\psi} \psi_{F, t}\right]
$$

where $\omega_{s} \equiv 1+\gamma(2-\gamma)(\sigma \eta-1)>0$ and $\omega_{\psi} \equiv 1+\gamma(\sigma \eta-1)>0$ are the elasticities of relative output to the domestic currency relative price of imports and the l.o.p gap respectively, with $\omega_{s} \geq \omega_{\psi}$.

The expression in (28) makes clear that any movement in relative output requires, in equilibrium, an adjustment in relative prices, summarized by the right hand side of the above equation. Consider the case, for instance, of a rise in domestic output relative to the rest of the world. Equilibrium requires a real depreciation, which in turn can be achieved in two ways: either a fall in the domestic currency price of domestic goods (relative to foreign goods, i.e., a rise in $s_{t}$ ) or a nominal depreciation triggering a deviation from the law of one price for imports (i.e., a rise in $\psi_{F, t}$ ).

\subsection{Policy Target in the Rest of the World}

Let's first describe how the equilibrium looks like in the rest of the world. The equilibrium real marginal cost is given by: 


$$
m c_{t}^{*}=(\sigma+\varphi) y_{t}^{*}-(1+\varphi) z_{t}^{*}
$$

which is simply the closed economy (i.e., obtained for $\gamma=0$ ) version of equation (24). Therefore the natural (flexible-price) level of output in the world economy easily obtains by imposing $m c_{t}^{*}=0$ (which implies $\pi_{t}^{*}=0$ ) :

$$
\bar{y}_{t}^{*}=\left(\frac{1+\varphi}{\sigma+\varphi}\right) z_{t}^{*}
$$

As in a canonical sticky-price model with Calvo price staggering, under fully flexible prices the output gap will be completely stabilized, i.e.,

$$
\widetilde{y}_{t}^{*}=y_{t}^{*}-\bar{y}_{t}^{*}=0
$$

Throughout it is assumed that the monetary authority in the rest of the world aims at replicating the flexible price allocation by simultaneously stabilizing inflation and the output gap. It is well known that such a policy also coincides with the first best outcome. $^{12}$

\subsection{Flexible Domestic Prices}

In this section we describe the equilibrium dynamics in the small economy under the assumption that domestic producer prices are flexible. This is useful to formally derive two results. First, that nominal exchange rate volatility is linked to the degree of pass-through. Second, that for a sufficiently low degree of pass-through the l.o.p gap must respond positively to a (relative) productivity shock.

In the case of flexible domestic prices the pricing equation (13) yields a constant markup. Therefore we can assume, without loss of generality, that domestic prices remain fixed at their optimal level, as firms would have no incentive to deviate from such a state of affairs. By imposing a constant markup in equation (24) and substituting equation (28) an expression for the domestic flexible price level of output reads:

$$
\bar{y}_{t}=\bar{y}_{t}^{n}-\left(\frac{\omega_{s}-\omega_{\psi}}{\sigma+\varphi \omega_{s}}\right) \bar{\psi}_{F, t}
$$

\footnotetext{
${ }^{12}$ Goodfriend and King (1997). Woodford (2002) discusses under which conditions such a policy corresponds also to maximizing a second order approximation of households' welfare.
} 
where $\bar{y}_{t}^{n} \equiv\left(\frac{\omega_{s}(1+\varphi)}{\sigma+\varphi \omega_{s}}\right) z_{t}+\left(\frac{\sigma\left(1-\omega_{s}\right)}{\sigma+\varphi \omega_{s}}\right) y_{t}^{*}$ denotes the natural level of output, i.e., the one that would obtain in the case of both flexible domestic prices and complete passthrough. Below we show how to obtain a reduced form expression for $\bar{\psi}_{F, t}$. Notice also that the two measures of output gap exactly coincide in the special case $\omega_{s}=\omega_{\psi}$.

The l.o.p gap can then be written

$$
\bar{\psi}_{F, t}=\bar{e}_{t}-\bar{p}_{F, t}
$$

and the terms of trade

$$
\bar{s}_{t}=\bar{e}_{t}-\bar{\psi}_{F, t}
$$

By using equation (28) and noticing that $\bar{s}_{t}=\frac{\sigma}{\omega_{s}}\left(\bar{y}_{t}-y_{t}^{*}\right)-\frac{\omega_{\psi}}{\omega_{s}} \bar{\psi}_{F, t}$ the nominal exchange rate can be written as

$$
\bar{e}_{t}=\frac{\sigma}{\omega_{s}}\left(\bar{y}_{t}-y_{t}^{*}\right)+\left(1-\frac{\omega_{\psi}}{\omega_{s}}\right) \bar{\psi}_{F, t}
$$

which can be rearranged, using (32), to obtain

$$
\bar{e}_{t}=\bar{e}_{t}^{n}+\left(\frac{\varphi\left(\omega_{s}-\omega_{\psi}\right)}{\sigma+\varphi \omega_{s}}\right) \bar{\psi}_{F, t}
$$

where $\bar{e}_{t}^{n} \equiv \frac{\sigma(1+\varphi)}{\sigma+\varphi \omega_{s}}\left(z_{t}-z_{t}^{*}\right)$ is the natural nominal exchange rate. Hence notice that, as long as $\omega_{s} \neq \omega_{\psi}$, deviations from the law of one price contribute to the volatility of the nominal exchange rate beyond the one implied by its natural level. Therefore the model seems consistent with the view that a lower degree of pass-through is associated with higher exchange rate volatility. ${ }^{13}$ Intuitively, the lower the passthrough the larger will be the nominal exchange rate variation required to achieve a given adjustment in real relative prices along the transition to the equilibrium.

Next it is instructive to derive a reduced-form expression for the l.o.p gap as a function of relative productivity. In Appendix A we show that the dynamic of the l.o.p gap can be written:

$$
\bar{\psi}_{F, t}=\Gamma\left(z_{t}-z_{t}^{*}\right)-\frac{\mu_{1}\left(\sigma+\varphi \omega_{s}\right)}{\sigma+\varphi \omega_{\psi}} \bar{p}_{F, t-1}
$$

\footnotetext{
${ }^{13}$ See e.g., Betts and Devereux (2000). However Devereux and Engle (2002) show that a low passthrough is a necessary but not sufficient condition for generating both an exchange rate volatility in line with the data and to be consistent with the so-called Baxter-Stockman disconnect puzzle (according to which movements in relative prices seem delinked from the ones of real quantities).
} 
where $\mu_{1}<1$ and $\Gamma \equiv \frac{\sigma(1+\varphi)}{\sigma+\varphi \omega_{\psi}}\left(1-\frac{\left(\sigma+\varphi \omega_{s}\right) \beta \mu_{1} \lambda_{F}}{\left(\sigma+\varphi \omega_{\psi}\right)\left(1-\rho \beta \mu_{1}\right)}\right)$. One can easily show that $\Gamma>0$ for a sufficiently low degree of pass-through, which in turn implies that the l.o.p gap must rise in response to a rise in domestic productivity. ${ }^{14}$ This result, which indeed depends on importers feeding nominal exchange rate movements on domestic currency import prices only gradually, will be useful below in our analysis of inflation dynamics in response to productivity shocks.

\subsection{The Supply Block}

We now proceed by illustrating how the introduction of incomplete pass-through affects the supply side relationships of the model. Let's define the output gap as the percentage deviation of current output from the natural level of output, i.e.,

$$
\widetilde{y}_{t} \equiv y_{t}-\bar{y}_{t}^{n}
$$

where again it is important to recall that the natural level of output is the one that would obtain under both flexible prices and complete pass-through. Equation (28), in turn, implies that the output gap is proportional to both the (domestic) terms of trade gap and the l.o.p gap:

$$
\widetilde{y}_{t}=\frac{\omega_{s}}{\sigma} \widetilde{s}_{t}+\frac{\omega_{\psi}}{\sigma} \psi_{F, t}
$$

Therefore the equilibrium real marginal cost (24) can be written, after combining with (38), as

$$
m c_{t}=\left(\varphi+\frac{\sigma}{\omega_{s}}\right) \widetilde{y}_{t}+\left(1-\frac{\omega_{\psi}}{\omega_{s}}\right) \psi_{F, t}
$$

Hence the presence of incomplete pass-through breaks down the proportionality relationship between the real marginal cost and the output gap which typically characterizes the canonical sticky-price model with imperfectly competitive markets. With incomplete pass-through, in fact, the real marginal cost is proportional to both the deviations of current output from its natural level and to the deviations from the law of one price. In response to productivity shocks the potentially contrasting equilibrium behavior of these two determinants of the real marginal cost will be the key

\footnotetext{
${ }^{14}$ In particular $\Gamma>0$ is satisfied for $\lambda_{F}<\frac{\left(\sigma+\varphi \omega_{\psi}\right)\left(1-\rho \beta \mu_{1}\right)}{\left(\sigma+\varphi \omega_{s}\right) \beta \mu_{1}}$, which in turn requires a sufficiently low degree of pass-through, i.e., a sufficiently high $\theta_{F}$.
} 
to understand the policy trade-off faced by the monetary authority. ${ }^{15}$ The analysis below will further elaborate on this point.

Notice that the expression for the equilibrium real marginal cost in (39) allows an interesting interpretation of the deviations from the law of one price as endogenous supply shocks. In fact, by replacing (39) in (15) one obtains

$$
\pi_{H, t}=\beta\left\{E_{t} \pi_{H, t+1}\right\}+\kappa_{y} \widetilde{y}_{t}+\kappa_{\psi} \psi_{F, t}
$$

where $\kappa_{y} \equiv \lambda_{H}\left(\varphi+\frac{\sigma}{\omega_{s}}\right)$ and $\kappa_{\psi} \equiv \lambda_{H}\left(1-\frac{\omega_{\psi}}{\omega_{s}}\right)$. The result in equation (36) establishes that the term $\psi_{F, t}$ will rise in response to a rise in domestic productivity (for a sufficiently low degree of pass-through). Hence (for any given output gap) positive movements in inflation can result from endogenous movements in the l.o.p gap which can in turn be induced by (efficient) positive variations in productivity. This contrasts with a practice that has become common in models of the New Keynesian Phillips curve of "appending" (inefficient) cost-push terms to the right hand side of (40) as a proxy for supply shocks.

By solving equation (40) forward it yields:

$$
\pi_{H, t}=E_{t}\left\{\sum_{k=0}^{\infty} \beta^{k}\left(\kappa_{y} \widetilde{y}_{t+k}+\kappa_{\psi} \psi_{F, t+k}\right)\right\}
$$

which implies that domestic inflation is entirely forward-looking, depending on current and expected future values of the output gap and of the l.o.p gap.

\subsubsection{CPI-based Aggregate Supply}

In this section we show that the interpretation of the deviations from the law of one price as (endogenous) supply shocks continues to hold also when the broader CPI measure of inflation is considered. Recall that, up to a log-linear approximation, CPI inflation can be written as a convex combination of both domestic and import price inflation (as from equation (6)). It is again natural to express the equilibrium in terms of deviations from the frictionless allocation (where domestic flexible prices and complete pass-through both hold).

\footnotetext{
${ }^{15}$ One can also notice that the theory-based measure of the output gap implied by this setup is one in which the same output gap is proportional not only to the labor share (via the real marginal cost) but also to the l.o.p gap, which is another observable variable. The same would not hold in the case of complete pass-through, where one would recover the same proportionality between labor share and real marginal cost that characterizes prototypical closed economy models.
} 
By combining (24), (15), (19) and (38) one obtains the following expression for a CPI-based aggregate supply curve:

$$
\pi_{t}=\beta E_{t} \pi_{t+1}+\kappa_{y}^{c} \widetilde{y}_{t}+\kappa_{\psi}^{c} \psi_{F, t}
$$

where $\kappa_{y}^{c} \equiv(1-\gamma) \kappa_{y}$ and $\kappa_{\psi}^{c} \equiv(1-\gamma) \kappa_{\psi}+\gamma \lambda_{F}$.

Therefore, like domestic producer inflation, CPI inflation as well features a Phillips curve forward-looking representation. The novelty of the framework with incomplete pass-through is the second term on the right hand side. A rise in the l.o.p gap, for a given output gap, causes a rise in CPI inflation. A full stabilization of inflation, then, would require a fall in the output gap. Furthermore, notice that $\sigma=\eta=1$ implies $\kappa_{\psi}^{c}=\gamma \lambda_{F}>0$. Hence deviations from the law of one price continue to affect CPI inflation even in the special case of $\sigma=\eta=1$. This will be important below to qualify an additional existing trade-off between the stabilization of the output gap and of the CPI measure of inflation.

\subsection{The Demand Block}

To complete the description of the model it is useful to rewrite in a more compact form the aggregate demand equations as well. Notice, first, that by using (22) one can rewrite the market clearing condition as:

$$
y_{t}=\left(\frac{\omega_{s}}{1-\gamma}\right) c_{t}+\left(1-\frac{\omega_{s}}{1-\gamma}\right) c_{t}^{*}-\left(\frac{\gamma \eta}{1-\gamma}\right) \psi_{F, t}
$$

By substituting (43) into (4) and making use of the definition of the output gap and of equation (6) one can write the following aggregate demand equation:

$$
\widetilde{y}_{t}=E_{t}\left\{\widetilde{y}_{t+1}\right\}-\frac{\omega_{s}}{\sigma}\left(r_{t}-E_{t}\left\{\pi_{H, t+1}\right\}-\overline{r r}_{t}\right)+\Gamma_{y} E_{t}\left\{\Delta \psi_{F, t+1}\right\}
$$

where $\Gamma_{y} \equiv\left(\frac{\gamma(1-\gamma)(\sigma \eta-1)}{\sigma}\right)$ and $\overline{r r}_{t} \equiv \sigma\left(\frac{\varphi\left(\omega_{s}-1\right)}{\sigma+\varphi \omega_{s}}\right) E_{t}\left\{\Delta y_{t+1}^{*}\right\}-\left(\frac{\sigma(1-\rho)(1+\varphi)}{\sigma+\varphi \omega_{s}}\right) z_{t}$ is the natural real interest rate. Notice that the natural real rate depends not only on domestic productivity, but also on the expected growth in world output.

Equation (44) shows that, to the extent that $\sigma \eta>1$, expected changes in the output gap are negatively related to expected future changes in the l.o.p gap. By using (38), an equivalent way of rewriting equation (44) emphasizes the direct link between the output gap and the terms of trade gap $\widetilde{s}_{t}$ : 


$$
\widetilde{y}_{t}=E_{t}\left\{\widetilde{y}_{t+1}\right\}-\frac{\omega_{s} \Omega_{y}}{\sigma}\left(r_{t}-E_{t}\left\{\pi_{H, t+1}\right\}-\overline{r r}_{t}\right)-\frac{\omega_{s} \Omega_{y}}{\omega_{\psi}} \Gamma_{y} E_{t}\left\{\Delta \widetilde{s}_{t+1}\right\}
$$

where $\Omega_{y} \equiv \frac{\omega_{\psi}}{\sigma\left(\omega_{\psi}+\gamma(1-\gamma)((\sigma \eta-1))\right.}>0$. Hence expected changes in the output gap are positively related to expected future changes in the terms of trade gap.

\subsection{Breaking the Canonical Representation}

One result of the recent open economy New Keynesian optimizing framework is that the model's equilibrium dynamics can be represented in a output gap-inflation space (a so called canonical representation) which is isomorphic to its closed economy counterpart. The effect of adding the openness dimension would result only in the slope coefficients of the standard optimizing aggregate demand and supply relationships being modified. By considering the joint system described by the supply equation (40) and the demand equation (44) it stands clear that the introduction of incomplete pass-through has the effect of breaking the isomorphism between the closed and the open economy version of the canonical sticky-price model. ${ }^{16}$ To better understand this it is useful to analyze the monetary policy channels to inflation in the present model. First, there is a typical aggregate demand channel. This is common to both a closed and an open economy. Namely, changes in the nominal interest rate affect the real rate and the output gap via equation (44) and in turn inflation via both (40) and (42). In an open economy this channel is strengthened by the expenditure switching effect that works through changes in the terms of trade and in turn in the trade balance. With complete pass-through this channel affects only the sensitivity of output gap movements to the real interest rate. In that case, as from equation (38) under $\psi_{F, t}=0$, the terms of trade are simply proportional to the output gap, and their effect on demand simply feeds in via a modification of the slope of the aggregate demand equation. With incomplete pass-through there is an independent (aggregate demand) l.o.p channel to inflation that works via equation (44). This is the first factor that contributes to breaking the isomorphism between closed and open economy representations of the standard optimizing sticky-price model. ${ }^{17}$

The second channel to inflation in the model summarizes a series of aggregate

\footnotetext{
${ }^{16}$ See Gali and Monacelli (2002) and Clarida, Gali and Gertler (2002) for open economy models in which the isomorphism still holds due to the presence of complete pass-through.

${ }^{17}$ However notice that such isomorphism continues to hold in the extreme cases of $\gamma=0$ (closed economy) and $\gamma=1$ (consumption basket of the small economy coinciding with the one of the foreign economy), as well as in the special case of $\sigma=\eta=1$
} 
supply effects. First, the nominal exchange rate affects CPI inflation directly. This effect is obviously de-emphasized with incomplete pass-through. Second, the nominal exchange rate affects the terms of trade, the product wage and the real marginal cost via equation (24). We have already shown above that, via equation (39), this results in an independent supply-side channel linking the l.o.p gap to inflation (both producer and CPI), and hence in a second channel that alters the result of isomorphism.

\section{Policy Trade-offs in the Small Economy}

We now turn to the illustration of how the introduction of incomplete pass-through can crucially shape the range of trade-offs faced by the monetary authority of the small economy. We first have the following result:

- Under incomplete pass-through, and under the assumption that $\sigma \eta>1$, the domestic producer flexible price allocation is no longer feasible. Therefore the monetary authority faces a trade-off between stabilizing producer inflation variability and stabilizing either the output gap or the l.o.p gap:

$$
\operatorname{var}\left(\pi_{H, t}\right)=0 \longrightarrow \operatorname{var}\left(\widetilde{y}_{t}\right)>0, \operatorname{var}\left(\psi_{F, t}\right)>0
$$

The intuition follows directly from the real marginal cost equation (39). Consider, for instance, a rise in the relative productivity of the domestic economy. This, ceteris paribus, tends to lower the output gap and to exert a downward pressure on the real marginal cost. However it also implies a nominal depreciation and, considering the result in equation (36), also a rise in the l.o.p gap for a sufficiently low degree of pass-through. Any attempt to stabilize the output gap by lowering interest rates would then boost the nominal depreciation and therefore imply a further rise in the l.o.p gap. Therefore the monetary authority cannot simultaneously stabilize the domestic markup and target the law of one price. The novel aspect of this result is that this trade-off arises endogenously in response to (efficient) productivity shocks. ${ }^{18}$ The derivation of a CPI-based aggregate supply curve in equation (42) is useful to understand that the monetary authority not only faces a trade-off between stabilizing domestic inflation and the output gap but also between stabilizing the CPI measure of inflation and the output gap. We have the following result:

\footnotetext{
${ }^{18}$ Recall, however, that in the special case in which $\omega_{s}=\omega_{\psi}$ movements in the l.o.p gap do not affect the domestic real marginal cost, and therefore the trade-off between domestic inflation and output gap variability is not binding, exactly like in the case of complete pass-through.
} 
- Under incomplete pass-through, and regardless of the values assumed by the parameters $\sigma$ and $\eta$, it is unfeasible for the monetary authority to simultaneously stabilize CPI inflation and the output gap:

$$
\operatorname{var}\left(\pi_{t}\right)=0 \longrightarrow \operatorname{var}\left(\widetilde{y}_{t}\right)>0, \operatorname{var}\left(\psi_{F, t}\right)>0
$$

The intuition follows naturally from the CPI-based aggregate supply curve (42). However, in this case, it is interesting to notice that the trade-off persists even in the case of $\sigma \eta=1$, given that $\Theta_{\psi}>0$. To understand this, notice that two are the channels through which incomplete pass-through has an effect on CPI inflation. First, by affecting the domestic real marginal cost through equation (39). Second, by rising imports inflation through equation (19). In the case $\sigma \eta=1$ the first channel is neutralized, while the second effect continues to hold given that $\kappa_{\psi}^{c}=\gamma \lambda_{F}$.

\section{Optimal Monetary Policy Design}

In this section we characterize the optimal monetary policy design problem. The focus of attention, similar to Woodford (2002) for the case of a closed economy, is on the nature of the optimal dynamic program for the monetary authority in the presence of households and firms adopting forward-looking decisions. The possibility of affecting future private sector's expectations gives rise to gains from commitment relative to a regime in which only discretionary optimization is feasible. This is a central insight of the recent analysis of optimal monetary policy in sticky-price models. ${ }^{19}$ The open economy dimension, along with the presence of incomplete pass-through, adds further wrinkles to the analysis. The presence of a l.o.p channel to inflation, as it stands clear from inspecting equation (42), calls for an optimal management of the deviations from the law of one price and therefore of both the nominal and the real exchange rate along the optimal path. Furthermore, and in order to affect future inflation expectations, such deviations from the law of one price must be optimally managed against the output gap path, with these two variables further interacting through the aggregate demand relationship summarized by equation (44).

The (endogenous) conflict between policy objectives discussed in the previous sections motivates the choice of our loss criterion. We assume that the domestic authority sets policy in order to minimize a quadratic loss function which penalizes the

\footnotetext{
${ }^{19}$ Woodford (2000), Clarida, Gali and Gertler (2000).
} 
variability of CPI inflation and output gap around some target values. In particular we assume that such targets are zero for both variables. ${ }^{20}$ The choice of including CPI inflation in the loss function appears the most natural. As pointed out in Svensson (2000) all small economies that have adopted regimes of inflation targeting have chosen to target a CPI measure of inflation, rather than a producer price or GDP measure, which would correspond to the index $\pi_{H}$ in this analysis. ${ }^{21}$

Before turning to the analysis of the optimal policy design problem, let me characterize the rational expectations equilibrium in the small economy.

Definition 1 Conditional on the definition of an appropriate monetary policy rule, and under the assumption that the world economy pursues a policy of strict price stability, a rational expectations equilibrium for the small economy can be computed as a set of processes $\left\{\pi_{t}, \pi_{H, t}, \widetilde{y}_{t}, \pi_{F, t}, \psi_{F, t}, e_{t}, r_{t}\right\}_{t=0}^{\infty}$ that solves the system of equations (10), (23), (40), (42), (19), (44), (6) for any given set of processes for the exogenous variables $\left\{\overline{r r}_{t}, z_{t}^{*}, \pi_{t}^{*}, r_{t}^{*}, \widetilde{y}_{t}^{*}\right\}_{t=0}^{\infty}$.

\subsection{Time Consistent Policy}

We begin by assuming, for the sake of exposition, that the monetary authority lacks a device that allows a commitment to a once-and-for-all plan at time 0 , and therefore

\footnotetext{
${ }^{20}$ The assumption that the target value for the output gap is zero implies that there is no bias in the average inflation rate resulting from discretionary optimization. However, and stemming from the forward looking nature of both measures of inflation, the response to technology shocks under discretionary optimization will still result in an inefficient outcome. See Woodford (1999a) for a detailed analysis in the context of a closed economy model.

${ }^{21}$ An obvious alternative would be to assume that the monetary authority tries to maximize the welfare of domestic households. Woodford (2000) shows how to obtain, within a closed economy model, a second order accurate approximation of households' utility and use it to solve a tractable quadratic control problem. In open economy forward-looking models with Calvo pricing this has been shown to be a much more complicated task, as argued in Benigno and Benigno (2002) and Gali and Monacelli (2002). In particular, in such models an accurate quadratic approximation of households' welfare can be obtained only under very specific assumptions on preferences and on the value of the international elasticity of substitution. The issue of how computing welfare maximizing polices in fully dynamic open economy models still remains a subject of research. See Faia and Monacelli (2003) for an alternative approach based on the direct solution of the Ramsey problem and on the explicit consideration of all the distortions characterizing the equilibrium of the economy. However, notice that by choosing to target CPI inflation the Central Bank is implicitly targeting a weighted average of both sources of nominal rigidities in the economy, namely stickiness in domestic prices and stickiness in the domestic currency prices of imported goods. This is likely to approximatevry closely the underlying welfare maximizing policy, as argued, for instance, in Corsetti and Pesenti (2002). Having said that, the current paper's scope remains the one of providing a tractable way of accounting for incomplete pass-through in small-scale optimizing monetary policy models.
} 
reoptimizes discretionally at each point in time. Let's define by $b_{w}>0$ the relative weight attached to output gap variability in the loss criterion. Hence the problem becomes the one of minimizing

$$
\frac{1}{2}\left[\pi_{t+k}^{2}+b_{w} \widetilde{y}_{t+k}^{2}\right]
$$

in each given date $t$, subject to the constraints given by equations (10), (23), (42), (19), (44), (6), (40). In this problem, and stemming from the assumed impossibility for the monetary authority to affect private sector's expectations, terms involving future expectations are treated parametrically. In Appendix $B$ we show that this problem leads to the following simple optimality condition linking inflation and the output gap in every period t:

$$
\widetilde{y}_{t}=-\Theta_{c} \pi_{t}, \text { all t }
$$

where $\Theta_{c} \equiv \frac{\kappa_{y}^{c}+\frac{\kappa_{\psi}^{c}}{a}}{b_{w}}>0$ and $a \equiv \frac{1+\gamma(\sigma \eta-1)}{\sigma}>0$. Condition (47) typically suggests that the monetary authority contracts real activity in response to a rise of CPI inflation above the target. The parameter $\Theta_{c}$ measures the magnitude of the implied optimal adjustment of the output gap. Notice that $\Theta_{c}$ is decreasing in the degree of passthrough $\theta_{F}$. In fact, the lower the pass-through (the higher $\theta_{F}$ ) the smaller the slope $\lambda_{F}$ of the import price equation (19). Notice also that by substituting (47) into (42) it yields

$$
\pi_{t}=\frac{\kappa_{\psi}^{c}}{1+\Theta_{c} \kappa_{y}^{c}} E_{t}\left\{\sum_{j=0}^{\infty}\left(\frac{\beta}{1+\Theta_{c} \kappa_{y}}\right)^{j} \psi_{F, t+j}\right\}
$$

The above expression shows that, under the optimal discretionary policy, CPI inflation must rise in response to both current and expected future deviations from the law of one price.

\subsubsection{A Contractionary Bias}

It is particularly interesting to notice that the higher $\kappa_{\psi}^{c}$, i.e., the higher the sensitivity of inflation to movements in the l.o.p gap, the larger will be the contraction in real activity associated to any given variation in inflation. This suggests the existence, as an effect of incomplete pass-through, of a policy contractionary bias. One way to analyze this issue more formally is by means of a thought experiment. Let's maintain that the monetary authority's problem is the one of minimizing (46). Yet let's assume 
that the same policy authority treats the deviations from the law of one price simply as exogenous shifters of the short-run Phillips curve (42). This strategy allows an interesting parallel with recent models in which the presence of a policy trade-off depends simply on ad-hoc cost push shocks. Hence the problem is now to choose $\pi_{t}$ and $\widetilde{y}_{t}$ period by period, given the vector of exogenous variables, $\left\{\overline{r r}_{t}, z_{t}^{*}, \pi_{t}^{*}, r_{t}^{*}\right\}$,to minimize (46) subject only to

$$
\pi_{t}=\digamma+\kappa_{y}^{c} \widetilde{y}_{t}
$$

where $\digamma \equiv \beta E_{t}\left\{\pi_{t+1}\right\}+\kappa_{\psi}^{c} \psi_{F, t}$ is a composite term which is taken as given by the policy authority in her maximization problem. Notice that in so doing the monetary authority not only recognizes that future private sector's expectations cannot be manipulated, but treats movements in the l.o.p gap as exogenous as well. The first order condition of this problem reads:

$$
\widetilde{y}_{t}=-\Theta_{x} \pi_{t}, \text { all } t
$$

where $\Theta_{x} \equiv \frac{\kappa_{y}^{c}}{b_{w}}>0$, with $\Theta_{x}$ measuring the sensitivity of the output gap to movements in inflation. Notice in particular that

$$
\Theta_{c}>\Theta_{x}
$$

The case just illustrated may be viewed as one in which the policy authority is treating deviations from the law of one price as exogenous cost push shocks. Or, alternatively, as one in which the policy authority does not face any trade-off between the aggregate demand and the exchange rate channel to inflation. In the more general case, though, when movements in the l.o.p gap are instead treated as endogenous, the monetary authority has to recognize that by lowering interest rates in response to a rise in productivity it will also trigger a nominal depreciation and therefore a rise in the l.o.p gap, which tends to rise inflation even further. Hence, and relative to the case in which deviations from the law of one price were treated as exogenous shocks, for any given initial rise in inflation the policymaker would have to contract the output gap more sharply. The former example also illustrates that the main effect of incomplete pass-through on the optimal policy design problem is that the aggregate demandoutput gap channel and the exchange rate channel to inflation must be optimally managed one against the other. 


\subsection{Optimal Plan}

In the case in which commitment is feasible as of time zero, the policy authority is assumed to choose a state-contingent plan $\left\{\pi_{t}, \pi_{H, t}, \widetilde{y}_{t}, \pi_{F, t}, \psi_{F, t}, e_{t}, r_{t}\right\}_{t=0}^{\infty}$ to minimize the discounted sum of losses:

$$
\frac{1}{2} E_{t}\left\{\sum_{j=0}^{\infty} \beta^{j}\left[\pi_{t+j}^{2}+b_{w} \widetilde{y}_{t+j}^{2}\right]\right.
$$

subject to the constraints (10), (23), (42), (19), (44), (6), (40). For the sake of exposition the details of such problem are deferred to Appendix B. An evaluation of the equilibrium dynamics along the optimal program will require a numerical simulation of the model.

\section{Dynamics under the Optimal Policy}

In this section we compute numerically the equilibrium dynamics of selected variables conditional on the optimal policy program and in response to an unexpected rise in domestic productivity (relative to the rest of the world). The benchmark calibration employed is as follows. We assume $\beta=0.99, \sigma=1, \eta=1.5, \varphi=3$. The parameter $\theta_{H}$, which governs the degree of stickiness of domestic prices, is set equal to 0.75 , a value consistent with an average period of one year between price adjustments. The parameter $\theta_{F}$, which governs the degree of pass-through, is also set to a benchmark value of 0.75 , but will then vary depending on the sensitivity analysis conducted. The persistence of the productivity process is set $\rho=0.9$ and its standard deviation is calibrated to take a unitary value. The relative weight attached to output gap volatility $b_{w}$ in the monetary authority's loss function is set equal to a baseline value of 0.2 (although it will be varied in the analysis below).

All parameters describing the equilibrium in the foreign economy are assumed to take values identical to the ones in the small open economy. In addition, the small economy is characterized by an openness index $\gamma=0.4$.

Figure 1 compares the response of selected variables under the optimal commitment policy (solid line) to the one under discretionary optimization (dashed line). Several aspects are worth emphasizing. First, under discretion and in response to the rise in relative productivity, CPI inflation and the l.o.p gap both tend to rise on impact, while the output gap falls below the target value. The important point to notice is that the impact effect of the positive productivity shock on inflation and 
output gap resembles the one in response to a cost-push shock. The rise in the l.o.p gap, in particular, is the result of a nominal depreciation combined with a sluggish movement in the domestic currency price of imports.

Second, under commitment the Central Bank trades off some volatility in the output gap in order to achieve, relative to discretion, a stronger stabilization of the l.o.p gap and in turn a stronger stabilization of the variables of interest for her loss criterion. The key is that under commitment the Central Bank can manipulate the expectations about the future behavior of the exchange rate and therefore indirectly of the l.o.p gap. In this case the initial nominal exchange rate depreciation is strongly dampened. Expectations of a persistent nominal appreciation are then generated to smooth the current rise in the l.o.p gap and in turn induce a fall in the expected future l.o.p gap. This produces an overshooting in inflation which is observed to fall persistently below steady state after a few periods. Correspondingly, and given the trade-off between the stabilization of the output gap and of the l.o.p gap, the output gap rises above its long run value for several periods. It is important to notice that this entails a possibly larger volatility of the output gap under commitment relative to discretion (see the quantitative results below). Yet the larger instability in the output gap is traded off against a smoother path of the l.o.p gap, a strategy which yields a more stable path of inflation.

Third, a typical feature of the optimal commitment policy in forward looking models emerges here, namely that the (CPI) price level exhibits a stationary dynamic. $^{22}$ This feature is the result of the possibility of the commitment plan to be history dependent. On the contrary, under discretion, any temporary shock affecting inflation at time $t$ will have a permanent effect on the price level, for the policy authority cannot commit to a certain future path for both the output gap and the l.o.p gap that allows future policy to be conditional on past shocks, and therefore undo the deviations of the price level from a stationary path (or eventually from a trend in the case of a positive value for the inflation target). However, while the CPI level exhibits a stationary dynamic under the optimal program, the same does not hold for the producer domestic price level.

The results above already illustrate the gains from commitment that characterize the optimal policy design problem. It is worth recalling that such gains emerge endogenously in response to efficient domestic productivity shocks. The statistics reported in Table 2 confirm this intuition. Second moments of selected variables

\footnotetext{
${ }^{22}$ See Woodford (1999a) for a discussion in the context of a closed economy models.
} 
under commitment are compared to the ones under discretionary optimization. Two scenarios are reported. The first is labelled low weight on the output gap and corresponds to a value of $b_{w}=0.2$, while the second scenario features $b_{w}=0.5$, which is typically considered a high value in the literature. Two observations are in order. First, it stands clear that the optimal strategy, relative to the discretionary policy, trades off a larger output gap volatility for smoother deviations from the law of one price. This is particularly evident when the weight on output gap volatility is high. Second, notice that implementing the optimal commitment policy entails much less volatile nominal and real exchange rates relative to discretion. ${ }^{23}$ Hence the presence of incomplete pass-through builds a case for restricting exchange rate volatility but not for fixing exchange rates which would correspond to a suboptimal policy in our case.

\section{Simple Policy Rules}

It is almost conventional wisdom among researchers that, in practice, monetary policy is conducted according to targeting rules. Their virtues in terms of simplicity and transparency are often emphasized. In this section we investigate how the performance of three alternative simple rules is affected by the presence of incomplete pass-through: CPI targeting (CPIT), Domestic Producer Inflation Targeting (DIT) and Exchange Rate Peg (PEG). In the analysis we maintain the assumption that monetary policy in the rest of the world aims at replicating the flexible price allocation. In the case of CPIT the domestic authority follows a strategy which implies setting $\pi_{t}=0$ for all $t$. In the case of DIT the policy authority simply aims at stabilizing the rate of domestic producer price inflation, namely $\pi_{H, t}=0$ for all $t$. This outcome can be implemented if and only if, in turn, the domestic real marginal cost is stabilized, which implies $\widetilde{y}_{t}=-\frac{\kappa_{\psi}}{\kappa_{y}} \psi_{F, t}$. Hence, under DIT, the output gap is proportionally and inversely related to the l.o.p gap. In a PEG regime, the monetary authority of the small economy permanently fixes the nominal exchange rate vis a vis the rest of the world by implementing $r_{t}=r_{t}^{*}$ all t.

It is interesting to analyze the impact of imperfect pass-through on the relative volatility of selected variables across alternative policy rules. This is the content of the four panels in Figure 2, which display the effect of varying the degree of pass-through

\footnotetext{
${ }^{23}$ Notice that Table 1 reports second moments for nominal and real depreciation rates, as the corresponding levels are non-stationary in this context.
} 
(measured between 0 and 1 on the horizontal axis) on the volatility of output gap, domestic inflation, l.o.p gap and real exchange rate across the three policy regimes: DIT, CPIT and PEG. Notice, at first, that the volatility of all variables is unaffected by the degree of pass-through under a PEG. In particular, notice that a PEG implies a complete stabilization of the l.o.p gap, but also generates a larger volatility in both producer inflation and the output gap relative to DIT and CPIT. For a sufficiently high degree of pass-through this holds for CPI inflation as well. Overall this implies not only that such a regime is quantitatively further away from the optimal outcome relatively to the other two cases, but also, and most importantly, that a complete targeting of the law of one price cannot coincide with the optimal program.

The same figure suggests that the volatility of the output gap is always larger under CPIT than under DIT. This has an obvious implication in terms of the loss criterion employed in our analysis, i.e., DIT can be preferable to CPIT, for any given degree of pass-through, when the weight attached to output gap volatility in the Central Bank's loss criterion is relatively high. However, it stands clear that the lower the degree of pass-through, the closer the resemblance between CPIT and DIT. In the limiting case of null pass-through (i.e., $\theta_{F} \rightarrow 1$ ), the two regimes tend to coincide. This is easy to understand. In such a case, in fact, domestic currency import prices are completely fixed, so that stabilizing the producer price level corresponds exactly to stabilizing the CPI level. Finally, it is worth noticing that varying the degree of pass-through has also a substantial effect on the volatility of the real exchange rate. Such volatility is larger under DIT relative to CPIT for any degree of passthrough (with the exception of the limiting case of null pass-through), while it is again unaffected by the pass-through under a PEG.

\section{Conclusions}

We have constructed a framework to analyse the impact of incomplete exchange-rate pass-through in a fully forward-looking model of monetary policy. We have shown that the presence of incomplete pass-through (on imports price) alters the optimal monetary policy design problem in a fundamental way, by generating endogenously a trade-off between the stabilization of inflation and the stabilization of the output gap. Most interestingly, such trade-off holds independently of the measure of inflation (CPI or domestic producer) being targeted by the policymaker of the small economy. The reason is that, with incomplete pass-through, the domestic real marginal cost is 
proportional to both the output gap and the l.o.p gap, which is a measure, in our context, of the deviations from the law of one price. In equilibrium, it is unfeasible for the policy authority to simultaneously stabilize the output gap and the l.o.p gap. In fact, the same change in the interest rate (meant as the instrument of policy) has both an aggregate demand channel (affecting the output gap) and an exchange rate channel (affecting the l.o.p gap), with the sign of the former effect being opposite to the sign of the latter. A key result of the paper is that along the optimal commitment program the monetary authority has to optimally weigh one channel relative to the other. In particular, the optimal program involves a partial, yet not a complete, stabilization of the l.o.p gap. Another insight of our analysis is that the effectiveness of the exchange rate channel can be appreciated only within a comparison of the optimal commitment program to the discretionary policy. In the former case, the possibility of committing to a certain future path of the l.o.p gap (and therefore of the nominal exchange rate) is crucial for the minimization of the policy authority's loss criterion employed here. It is also worth noticing that, in general, an optimal commitment policy entails much smoother nominal and real exchange rates relative to discretion.

The framework developed in this paper, due to its tractability, lends itself to several possible extensions. For example, and given the particular form of the New Keynesian Phillips curve derived here, one could explore empirically the role of the l.o.p gap in the determination of the real marginal cost and therefore of the inflation dynamics. Furthermore, one may wish to extend this setup, along the lines of McCallum and Nelson (2001), to include a role for imported inputs of production along with imported consumer goods, and allow for possibly different degrees of pass-through on different types of goods prices. Finally, it would be particularly interesting to analyze, in our framework, the interaction between monetary policy regimes and degree of pass-through in a setup where the latter is determined endogenously. Important steps in this direction have been recently taken by Devereux, Engel and Storgaard (2003). 


\section{A Derivation of Equation (36)}

In this Appendix we show how to obtain equation (36). By substituting in (33) one can write an expression for the domestic currency price of imports as a function of relative productivity and the l.o.p gap:

$$
\bar{p}_{F, t}=\frac{\sigma(1+\varphi)}{\sigma+\varphi \omega_{s}}\left(z_{t}-z_{t}^{*}\right)-\left(\frac{\sigma+\varphi \omega_{s}}{\sigma+\varphi \omega_{\psi}}\right) \bar{\psi}_{F, t}
$$

Notice, in particular, that under PPT the above expression reduces to:

$$
\begin{aligned}
\bar{p}_{F, t}^{n} & =\bar{e}_{t}^{n}=s_{t}^{n} \\
& =\frac{\sigma(1+\varphi)}{\sigma+\varphi \omega_{s}}\left(z_{t}-z_{t}^{*}\right)
\end{aligned}
$$

i.e., the domestic currency price of imports moves exactly in line with the nominal exchange rate and the terms of trade.

By combining (52) with (19) one can express the dynamic of the imports price $\bar{p}_{F, t}$ in terms of a second order stochastic difference equation:

$$
\delta_{F} \bar{p}_{F, t}=\bar{p}_{F, t-1}+\beta E_{t}\left\{\bar{p}_{F, t+1}\right\}+\frac{\lambda_{F} \sigma(1+\varphi)}{\sigma+\varphi \omega_{\psi}}\left(z_{t}-z_{t}^{*}\right)
$$

where $\delta_{F} \equiv 1+\beta+\frac{\lambda_{F}\left(\sigma+\varphi \omega_{\psi}\right)}{\sigma+\varphi \omega_{s}}>1$. Under the assumption, for the sake of simplicity, that $\rho=\rho^{*}$, the above equation has a unique stationary solution of the form

$$
\bar{p}_{F, t}=\mu_{1} \bar{p}_{F, t-1}+\Omega\left(z_{t}-z_{t}^{*}\right)
$$

where $\mu_{1} \equiv \frac{\delta_{F}}{2}\left(1-\sqrt{1-\frac{4 \beta}{\delta_{F}^{2}}}\right)<1$ and $\Omega \equiv \frac{\lambda_{F} \beta \mu_{1} \sigma(1+\varphi)}{\left(\sigma+\varphi \omega_{\psi}\right)\left(1-\rho \beta \mu_{1}\right)}>0$. Hence it stands clear that the domestic currency price of imports must rise in response to a rise in relative productivity. Among other things, the elasticity of $\bar{p}_{F, t}$ to relative productivity depends positively on $\lambda_{F}$ (the slope of the imports price inflation equation (19)) and therefore on the degree of pass-through (with a low degree of pass-through implying a high $\theta_{F}$ and in turn a low $\lambda_{F}$ ).

Finally by substituting (35) and (19) into (33) one can derive an expression for the l.o.p gap which corresponds to equation (36) in the text. 


\section{B Deriving the Optimal Plan}

When the monetary authority has the possibility of committing as of time zero her quadratic control problem consists in choosing a state contingent plan $\left\{\pi_{t}, \pi_{H, t}, \widetilde{y}_{t}\right.$, $\left.\pi_{F, t}, \psi_{F, t}, e_{t}, r_{t}\right\}_{t=0}^{\infty}$ to minimize

$$
\frac{1}{2} E_{t}\left\{\sum_{j=0}^{\infty} \beta^{j}\left(\pi_{t+j}^{2}+b_{w} \widetilde{y}_{t+j}^{2}\right)\right.
$$

subject to the sequence of constraints (10), (23), (42), (19), (44), (6), (40) holding in all periods $t+j, j \geq 0$.

After taking first differences of (10) and combining with (23) one can setup the Lagrangian:

$$
\begin{aligned}
& \max -\frac{1}{2} E_{0}\left\{\sum_{t=0}^{\infty} \beta^{t}\left\{\left((1-\gamma) \pi_{H, t}+\gamma \pi_{F, t}\right)^{2}+b_{w} \widetilde{y}_{t}^{2}\right)\right. \\
& +2 \phi_{1, t}\left[\pi_{H, t}-\beta \pi_{H, t+1}-\kappa_{y} \widetilde{y}_{t}-\kappa_{\psi} \psi_{F, t}\right] \\
& +2 \phi_{2, t}\left[\widetilde{y}_{t}-\widetilde{y}_{t+1}+\frac{\omega_{s}}{\sigma}\left(r_{t}-\pi_{H, t+1}-\overline{r r}_{t}\right)-\frac{\gamma\left(\sigma \eta-\omega_{\psi}\right)}{\sigma}\left(\psi_{F, t+1}-\psi_{F, t}\right)\right] \\
& +2 \phi_{3, t}\left[\pi_{F, t}-\beta \pi_{F, t+1}-\lambda_{F} \psi_{F, t}\right] \\
& \left.\left.\left.+2 \phi_{4, t}\left[\psi_{F, t+1}-\psi_{F, t}-r_{t}+r_{t}^{*}-\pi_{t+1}^{*}+\pi_{F, t+1}\right)\right]\right\}\right\}
\end{aligned}
$$

where $\phi_{1, t+j}, \phi_{2, t+j}, \phi_{3, t+j}, \phi_{4, t+j}$ are Lagrange multipliers associated with the constraints at time $t+\mathrm{j}$. Notice that in this setup the constraint (6) has been substituted.

The first order conditions of this problem read:

$$
\begin{gathered}
\pi_{t}(1-\gamma)+\left(\phi_{1, t}-\phi_{1, t-1}\right)-\frac{\beta^{-1} \omega_{s}}{\sigma} \phi_{2, t-1}=0 \\
b_{w} \widetilde{y}_{t}-\kappa_{y} \phi_{1, t}+\phi_{2, t}-\beta^{-1} \phi_{2, t-1}=0 \\
\frac{\omega_{s}}{\sigma} \phi_{2, t}+\phi_{4, t}=0 \\
-\kappa_{\psi} \phi_{1, t}+\frac{\gamma\left(\sigma \eta-\omega_{\psi}\right)}{\sigma}\left(\phi_{2, t}-\beta^{-1} \phi_{2, t-1}\right)-\lambda_{F} \phi_{3, t}+\beta^{-1} \phi_{4, t-1}-\phi_{4, t}=0 \\
\gamma \pi_{t}+\phi_{3, t}-\phi_{3, t-1}+\beta^{-1} \phi_{4, t-1}=0
\end{gathered}
$$


Therefore an optimal plan is defined, for any given policy weight $b_{w}$, as a bounded solution $\left\{\pi_{H, t}, \widetilde{y}_{t}, \pi_{F, t}, \phi_{1, t}, \phi_{2, t}, \phi_{3, t}, \phi_{4, t}\right\}_{t=0}^{\infty}$ to the system of equations (10), (23), (40), (19), (44) and (56)-(60), along with the initial conditions $\phi_{1,-1}=\phi_{2,-1}=\phi_{3,-1}=$ $\phi_{4,-1}=0$.

\section{Optimal Policy under Discretion.}

When the policymaker lacks a commitment device the problem will be to minimize $\pi_{t}^{2}+b_{w} \widetilde{y}_{t}^{2}$ period by period taking as given the private sector's expectation terms contained in (10), (23), (42), (19), (44), (6), (40). The first order conditions of such problem are:

$$
\begin{gathered}
\pi_{t}(1-\gamma)+\phi_{1, t}=0 \\
b_{w} \widetilde{y}_{t}-\kappa_{y} \phi_{1, t}+\phi_{2, t}=0 \\
\frac{\omega_{s}}{\sigma} \phi_{2, t}+\phi_{4, t}=0 \\
-\kappa_{\psi} \phi_{1, t}+\frac{\gamma\left(\sigma \eta-\omega_{\psi}\right)}{\sigma} \phi_{2, t}-\lambda_{F} \phi_{3, t}-\phi_{4, t}=0 \\
\gamma \pi_{t}+\phi_{3, t}=0
\end{gathered}
$$

Therefore a Markov-perfect (time consistent) solution is a set of processes $\left\{\pi_{H, t}, \widetilde{y}_{t}\right.$, $\left.\pi_{F, t}, \phi_{1, t}, \phi_{2, t}, \phi_{3, t}, \phi_{4, t}\right\}$ that satisfies (61)-(65) along with (10), (23), (40), (19), (44) at all dates for any given policy preference weight $b_{w}$.

Conditions (61)-(65) above can be easily rearranged to obtain the following condition linking CPI inflation and the output gap under the optimal policy:

$$
\widetilde{y}_{t}=-\Theta_{c} \pi_{t}
$$

where $\Theta_{c} \equiv \frac{\kappa_{y}^{c}+\frac{\kappa_{\psi}^{c}}{a}}{b_{w}}$ and $a \equiv \frac{1+\gamma(\sigma \eta-1)}{\sigma}>0$, which is condition (47) in the text. 


\section{References}

[1] Adolfson, M. (2002). "Monetary Policy with Incomplete Exchange Rate PassThrough". Mimeo, Stockholm School of Economics.

[2] Benigno, Gianluca and P.P Benigno (2002). "Implementing Monetary Cooperation Through Inflation Targeting". CEPR Discussion Paper No 3226.

[3] Betts, Caroline and M.B. Devereux, 2000. "Exchange Rate Dynamics in a Model with Pricing-to-Market". Journal of International Economics, 50, 215-244.

[4] Calvo, Guillermo (1983). "Staggered Prices in a Utility Maximizing Framework", Journal of Monetary Economics 12 (3): 383-98.

[5] Burstein A., M. Eichenbaum and S. Rebelo (2002). "Why is Inflation so Low after Large Devaluations?", unpublished.

[6] Campa J. and Linda Goldberg (2002). "Exchange Rate Pass-Through into Import Prices: A Macro or Micro Phenomenon". Mimeo Federal Reserve Bank of New York.

[7] Chari, V.V, Patrick J.Kehoe and Ellen R. Mc Grattan (2002). "Can Sticky Price Models Generate Volatile and Persistent Real Exchange Rates?", Review of Economic Studies forthcoming.

[8] Clarida, Richard, Jordi Galí, and Mark Gertler (1999). "The Science of Monetary Policy: A New Keynesian Perspective". Journal of Economic Literature, vol. 37, 1661-1707.

[9] Clarida, Richard, Jordi Galí and Mark Gertler (2001). "Optimal Monetary Policy in Open Versus Closed Economies: An Integrated Approach". American Economic Review Papers and Proceedings, 91 (2), pp. 248-252.

[10] Corsetti, G. and Paolo Pesenti (2002). "International Dimensions of Optimal Monetary Policy". Mimeo University of Rome III and Federal Reserve Bank of New York.

[11] Devereux M. and Charles Engel (2001). "Monetary Policy in the Open Economy Revisited: Exchange Rate Flexibility and Price Setting Behavior", Mimeo. 
[12] Devereux M. and Charles Engel (2002). "Exchange Rate Pass-Through, Exchange Rate Volatility, and Exchange Rate Disconnect". Journal of Monetary Economics, June, 913-940

[13] Devereux M., Charles Engel and Peter Storgaard (2003). "Endogenous Exchange Rate Pass-Through when Nominal Prices are Set in Advance", Mimeo.

[14] Engel C. (1993). "Real Exchange Rates and Relative Prices: An Empirical Investigation". Journal of Monetary Economics 32.

[15] Engel C. (1999). "Accounting for U.S. Real Exchange Rate Changes," Journal of Political Economy 107, June, 507-538

[16] Engel C.(2002). "Expenditure Switching and Exchange Rate Policy". Mimeo, NBER Macroeconomics Annual.

[17] Faia E. and T. Monacelli (2003). "Ramsey Monetary Policy and International Relative Prices", IGIER Bocconi and Universitat Pompeu Fabra, Mimeo.

[18] Froot, Kenneth A. and Paul Klemperer (1989). "Exchange Rate Pass-Through when Market Shares Matters". American Economic Review 79:637-54.

[19] Gali Jordi and Tommaso Monacelli (2002). "Monetary Policy and Exchange Rate Volatility in a Small Open Economy". NBER w.p \#8905.

[20] Ghironi F.(2000). "Alternative Monetary Rules for a Small Open Economy : The Case of Canada". Boston College Econ. Dept. WP 466.

[21] Ghosh, Atish R. and Holger Wolf (1994). "Pricing in International Markets: Lessons from the Economist", NBER W.P \# 4806.

[22] Goldberg P. and M. Knetter (1997)."Goods Prices and Exchange Rates: What Have We Learned?" Journal of Economic Literature, September, 1243-1272.

[23] Goodfriend M. and B. King (1997). "The New Neoclassical Synthesis and the Role of Monetary Policy". National Bureau of Economic Research Macroeconomics Annual, pp.231-95.

[24] Knetter, Micheal M. (1989). "Price Discrimination by U.S and German Exporters". American Economic Review 79 (March): 198-210. 
[25] Knetter, Micheal M (1993). "International Comparisons of Pricing to Market Behavior". American Economic Review 83 (June), 473-86.

[26] Kydland, F.E. and E.C. Prescott (1977). "Rules rather than Discretion: The Inconsistency of Optimal Plans". Journal of Political Economy, 85, no.3 (June):473-491.

[27] McCallum B. and Edward Nelson (2000). "Monetary Policy for an Open Economy: An Alternative Framework with Optimizing Agents and Sticky Prices". Oxford Review of Economic Policy 16., 74-91

[28] Monacelli, Tommaso (1999). "Open Economy Policy Rules under Imperfect PassThrough. Mimeo", IGIER Universita' Bocconi.

[29] Monacelli, Tommaso (2002). "Into the Mussa Puzzle: Monetary Policy Regimes and the Real Exchange Rate in a Small Open Economy", Journal of International Economics forthcoming.

[30] Rotemberg, Julio J. and Micheal Woodford (1998). "Interest Rate Rules in an Estimated Sticky Price Model". In J.B Taylor (ed.), Monetary Policy Rules, Chicago: University of Chicago Press for NBER.

[31] Smets Frank and Raf Wouters (2002). "Openness, Imperfect Pass-Through and Monetary Policy", Journal of Monetary Economics, June.

[32] Schmitt-Grohe, Stephanie and Martin Uribe. "Closing Small Open Economy Models". Journal of International Economics, forthcoming

[33] Sutherland A. (2002). "Incomplete Pass-Through and the Welfare Effects of Exchange Rate Variability", Mimeo.

[34] Svensson Lars E.O (2000). "Open-Economy Inflation Targeting". Journal of International Economics, vol. 50, no. 1

[35] Woodford, Michael (2002). "Interest and Prices", Manuscript, forthcoming in Princeton University Press. 
Table 1

Volatility and Central Bank Loss under Alternative Monetary Policy Arrangements

\begin{tabular}{l|cc|cc|c}
\hline & \multicolumn{2}{c|}{ Low weight on Output Gap (bw=0.2) } & \multicolumn{1}{l}{ High weight on Output Gap (bw=0.5) } \\
\hline & Commitment & Discretion & Commitment & Discretion & \\
\hline CPI Inflation & 0.0002 & 0.0022 & 0.0004 & 0.0023 \\
Output Gap & 0.0012 & 0.0008 & 0.0005 & 0.0001 \\
Law of One Price Gap & 0.1101 & 0.5164 & 0.1452 & 0.5340 \\
Producer Inflation & 0.0024 & 0.0001 & 0.0015 & 0.0001 \\
Nominal Exchange Rate & 0.1472 & 0.5442 & 0.1865 & 0.5638 \\
Real Exchange Rate & 0.1396 & 0.4995 & 0.1748 & 0.5153 & \\
\hline CB Loss & 0.0004 & 0.0024 & 0.0006 & 0.0024
\end{tabular}

Note: The standard deviation of domestic and foreign productivity shocks is 1 . The cross-country correlation of the shocks is 0.7 . Exchange rates statistics refer to first differences. 
Figure 1. Domestic Productivity Shock: Commitment vs. Discretion

Output Gap

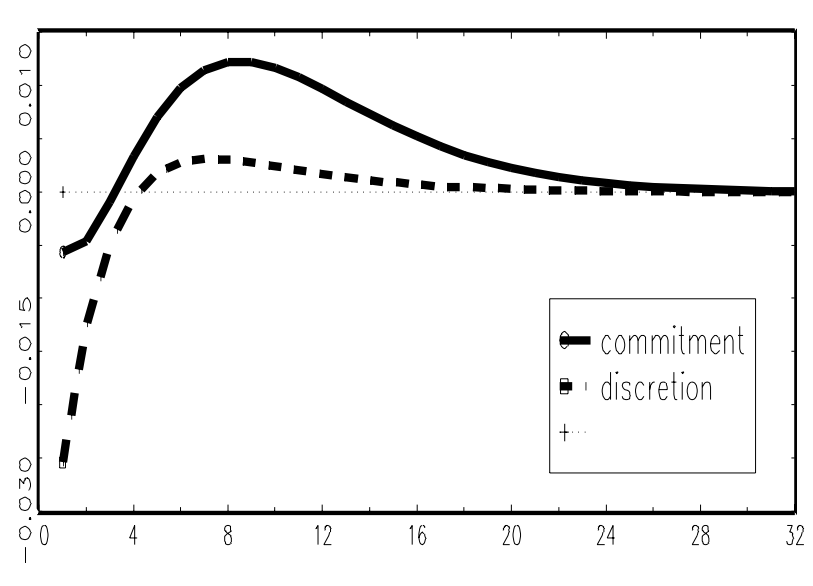

CPI Level

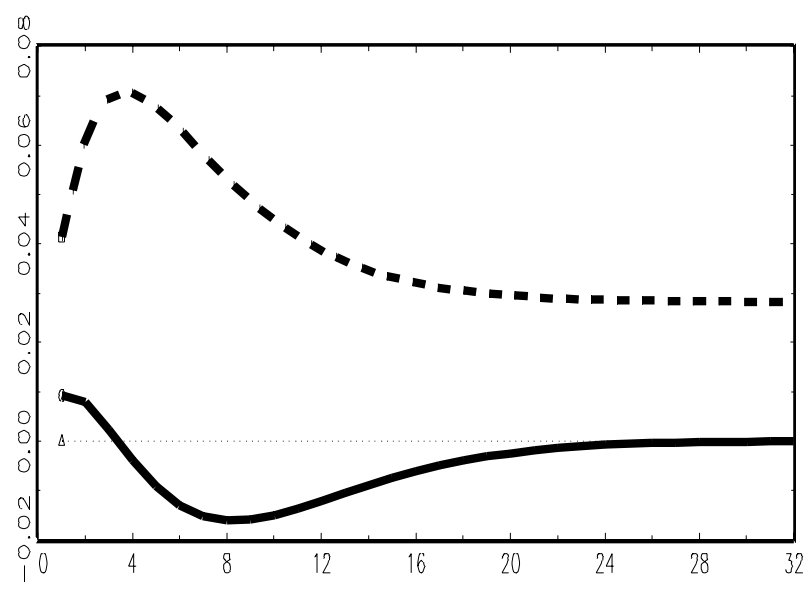

Law-of-one-price Gap

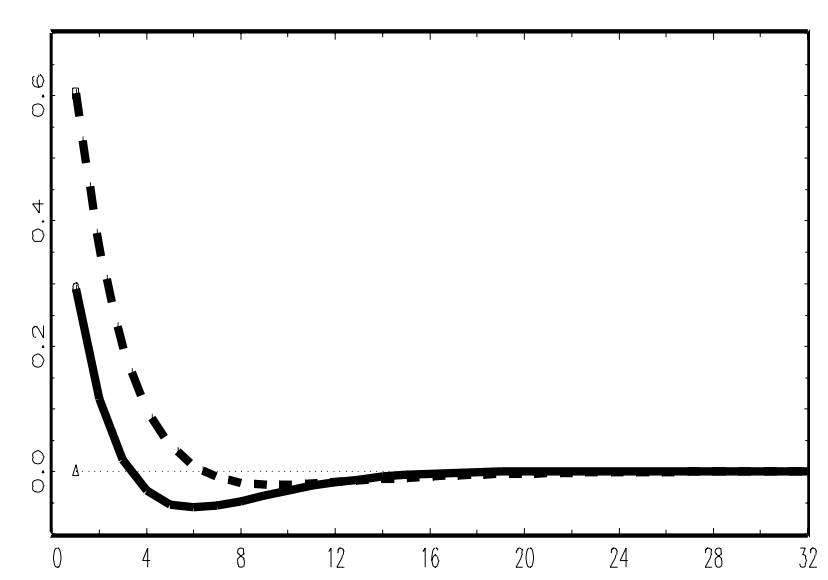

CPI inflation

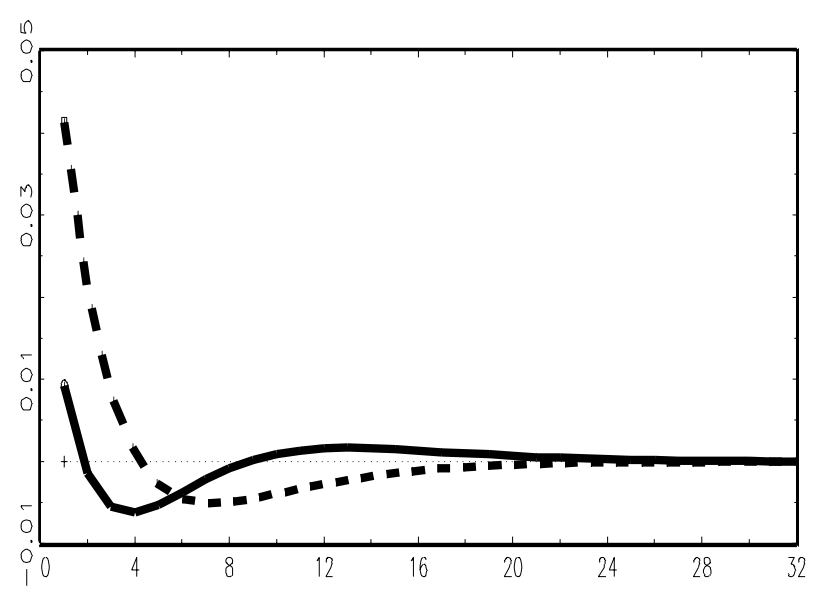

Producer Price Level

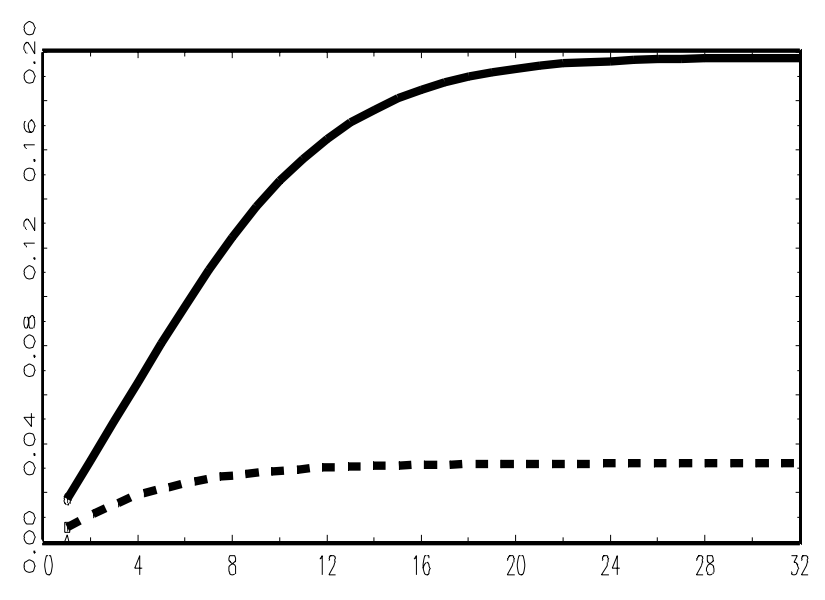

Nominal Exchange Rate

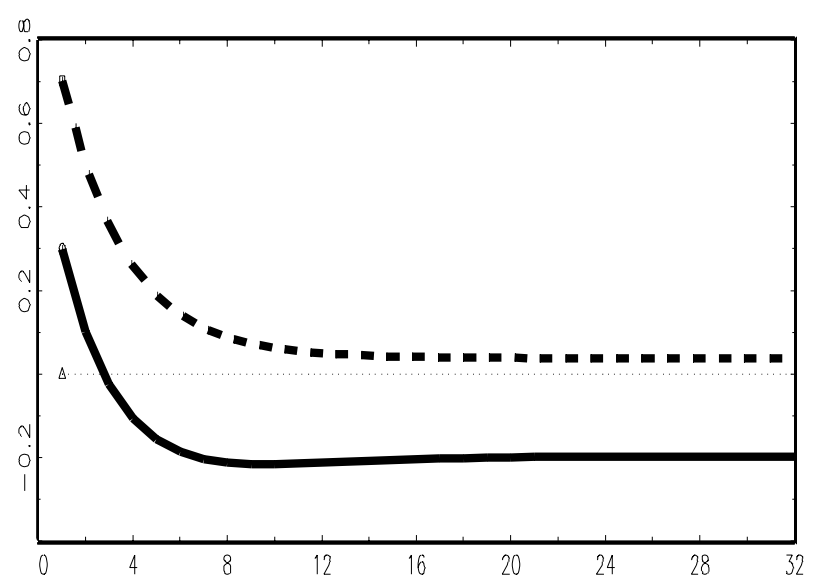




\section{Figure 2. Pass-through and Volatility under Alternative Policy Rules}

Output Gap

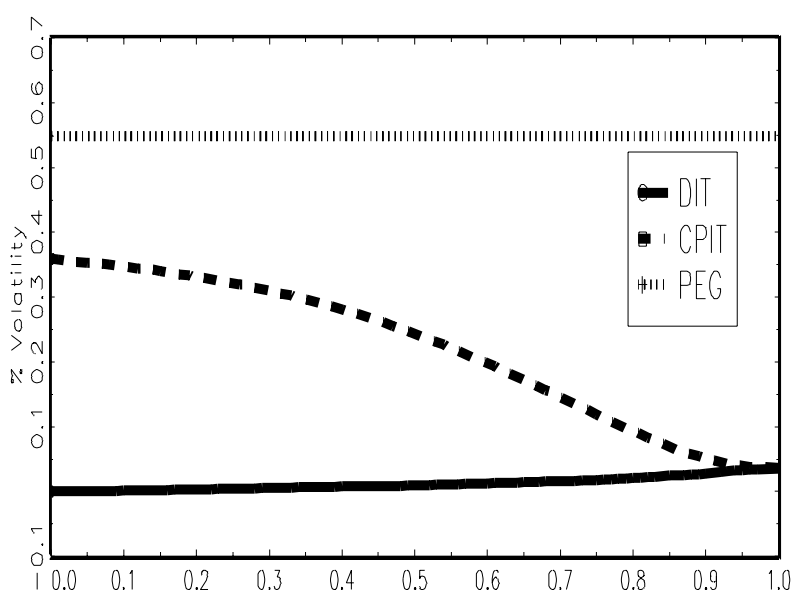

Producer Price Inflation

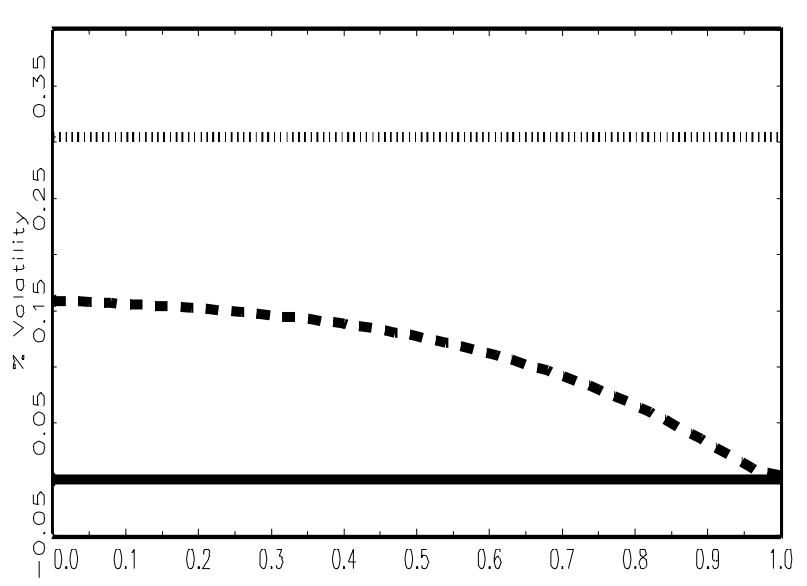

Nominal Exchange Rate

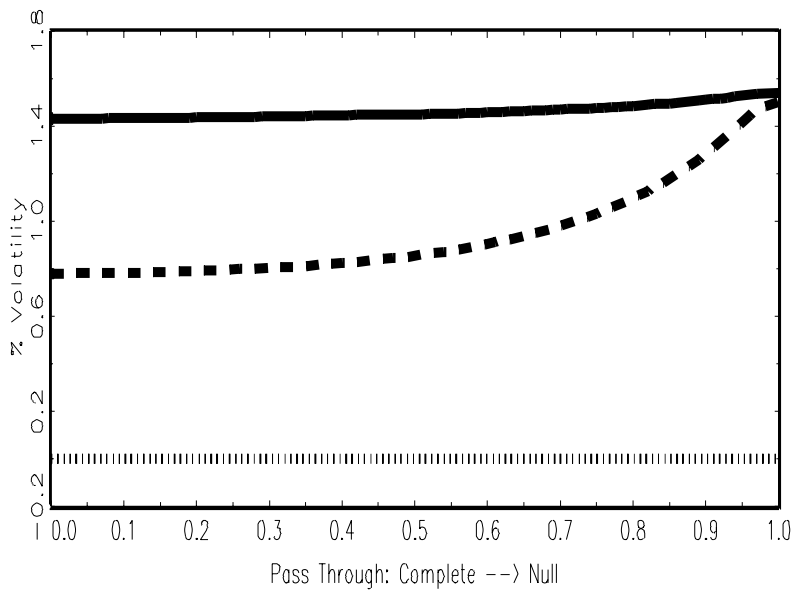

CPI Inflation

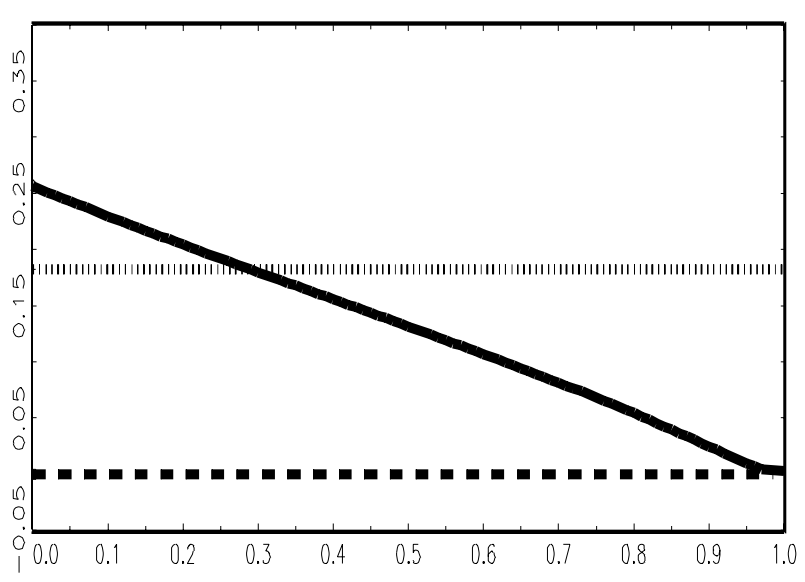

Deviation from Law of One Price

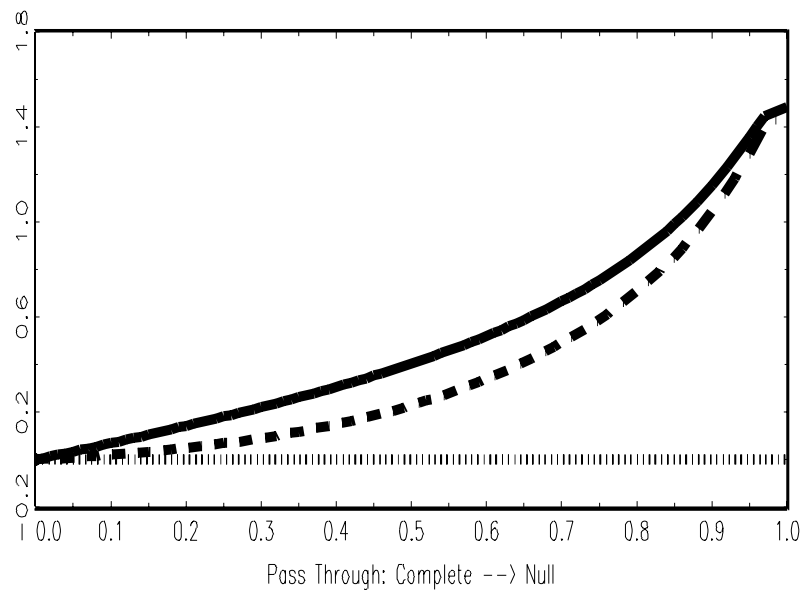

Real Exchange Rate

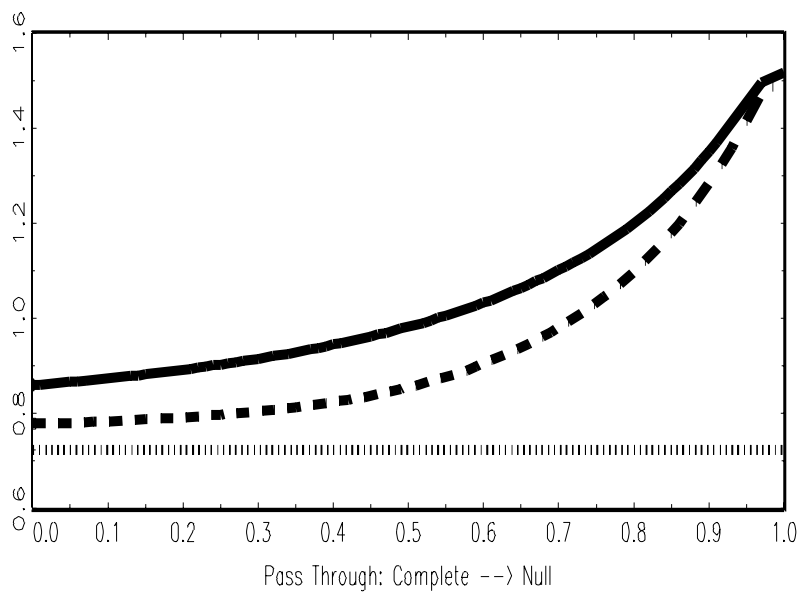




\section{European Central Bank working paper series}

For a complete list of Working Papers published by the ECB, please visit the ECB's website (http://www.ecb.int).

II 3 "Financial frictions and the monetary transmission mechanism: theory, evidence and policy implications” by C. Bean, J. Larsen and K. Nikolov, January 2002.

II4 "Monetary transmission in the euro area: where do we stand?" by I. Angeloni, A. Kashyap, B. Mojon, D. Terlizzese, January 2002.

II5 "Monetary policy rules, macroeconomic stability and inflation: a view from the trenches" by A. Orphanides, December 2001.

116 "Rent indices for housing in West Germany 1985 to 1998" by J. Hoffmann and C. Kurz., January 2002.

1 I7 "Hedonic house prices without characteristics: the case of new multiunit housing" by O. Bover and P. Velilla, January 2002.

118 "Durable goods, price indexes and quality change: an application to automobile prices in Italy, I988-98” by G. M. Tomat, January 2002.

119 "Monetary policy and the stock market in the euro area" by N. Cassola and C. Morana, January 2002.

120 "Learning stability in economics with heterogeneous agents" by S. Honkapohja and K. Mitra, January 2002.

I2I “Natural rate doubts” by A. Beyer and R. E. A. Farmer, February 2002.

122 "New technologies and productivity growth in the euro area" by F. Vijselaar and R. Albers, February 2002.

123 "Analysing and combining multiple credit assessments of financial institutions" by E. Tabakis and A. Vinci, February 2002.

124 "Monetary policy, expectations and commitment" by G. W. Evans and S. Honkapohja, February 2002.

125 “Duration, volume and volatility impact of trades” by S. Manganelli, February 2002.

126 "Optimal contracts in a dynamic costly state verification model" by C. Monnet and E. Quintin, February 2002.

127 "Performance of monetary policy with internal central bank forecasting" by S. Honkapohja and K. Mitra, February 2002.

128 “Openness, imperfect exchange rate pass-through and monetary policy" by F. Smets and R. Wouters, February 2002. 
129 "Non-standard central bank loss functions, skewed risks, and certainty equivalence" by A. al-Nowaihi and L. Stracca, March 2002.

130 "Harmonized indexes of consumer prices: their conceptual foundations" by E. Diewert, March 2002.

I3I "Measurement bias in the HICP: what do we know, and what do we need to know?" by M. A. Wynne and D. Rodrtguez-Palenzuela, March 2002.

132 "Inflation dynamics and dual inflation in accession countries: a "new Keynesian" perspective” by O. Arratibel, D. Rodrtguez-Palenzuela and C. Thimann, March 2002.

133 "Can confidence indicators be useful to predict short-term real GDP growth?" by A. Mourougane and M. Roma, March 2002.

134 "The cost of private transportation in the Netherlands, 1992-99" by B. Bode and J. Van Dalen, March 2002.

135 "The optimal mix of taxes on money, consumption and income" by F. De Fiore and P. Teles, April 2002.

I36 "Retail bank interest rate pass-through: the new evidence at the euro area level" by G. de Bondt, April 2002.

137 "Equilibrium bidding in the eurosystem's open market operations" by U. Bindseil, April 2002.

138 "New" views on the optimum currency area theory: what is EMU telling us?" by F. P. Mongelli, April 2002.

139 “On currency crises and contagion” by M. Fratzscher, April 2002.

I40 “Price setting and the steady-state effects of inflation" by M. Casares, May 2002.

|4| “Asset prices and fiscal balances” by F. Eschenbach and L. Schuknecht, May 2002.

142 "Modelling the daily banknotes in circulation in the context of the liquidity management of the European Central Bank”, by A. Cabrero, G. Camba-Mendez, A. Hirsch and F. Nieto, May 2002.

143 “A non-parametric method for valuing new goods”, by I. Crawford, May 2002.

144 "A failure in the measurement of inflation: results from a hedonic and matched experiment using scanner data”, by M. Silver and S. Heravi, May 2002.

145 "Towards a new early warning system of financial crises”, by M. Fratzscher and M. Bussiere, May 2002.

146 “Competition and stability - what's special about banking?", by E. Carletti and P. Hartmann, May 2002. 
147 "Time-to-build approach in a sticky price, sticky wage optimising monetary model, by M. Casares, May 2002.

I48 "The functional form of yield curves" by V. Brousseau, May 2002.

149 "The Spanish block of the ESCB multi-country model” by A. Estrada and A. Willman, May 2002.

150 "Equity and bond market signals as leading indicators of bank fragility" by R. Gropp, J. Vesala and G. Vulpes, June 2002.

I5I “G7 inflation forecasts” by F. Canova, June 2002.

152 "Short-term monitoring of fiscal policy discipline" by G. Camba-Mendez and A. Lamo, June 2002.

153 "Euro area production function and potential output: a supply side system approach" by A. Willman, June 2002.

154 "The euro bloc, the dollar bloc and the yen bloc: how much monetary policy independence can exchange rate flexibility buy in an interdependent world?" by M. Fratzscher, June 2002.

I55 "Youth unemployment in the OECD: demographic shifts, labour market institutions, and macroeconomic shocks" by J. F. Jimeno and D. Rodriguez-Palenzuela, June 2002.

I56 "Identifying endogenous fiscal policy rules for macroeconomic models" by J. J. Perez, and P. Hiebert, July 2002.

157 "Bidding and performance in repo auctions: evidence from ECB open market operations" by K. G. Nyborg, U. Bindseil and I. A. Strebulaev, July 2002.

158 "Quantifying Embodied Technological Change” by P. Sakellaris and D. J. Wilson, July 2002.

159 “Optimal public money” by C. Monnet, July 2002.

160 "Model uncertainty and the equilibrium value of the real effective euro exchange rate" by C. Detken, A. Dieppe, J. Henry, C. Marin and F. Smets, July 2002.

161 "The optimal allocation of risks under prospect theory" by L. Stracca, July 2002.

162 "Public debt asymmetries: the effect on taxes and spending in the European Union" by S. Krogstrup, August 2002.

163 "The rationality of consumers' inflation expectations: survey-based evidence for the euro area” by M. Forsells and G. Kenny, August 2002.

164 "Euro area corporate debt securities market: first empirical evidence" by G. de Bondt, August 2002. 
165 "The industry effects of monetary policy in the euro area" by G. Peersman and F. Smets, August 2002.

166 "Monetary and fiscal policy interactions in a micro-founded model of a monetary union" by R. M.W.J. Beetsma and H. Jensen, August 2002.

167 "Identifying the effects of monetary policy shocks on exchange rates using high frequency data" by J. Faust, J.H. Rogers, E. Swanson and J.H. Wright, August 2002.

168 "Estimating the effects of fiscal policy in OECD countries" by R. Perotti, August 2002.

169 “Modelling model uncertainty” by A. Onatski and N. Williams, August 2002.

170 "What measure of inflation should a central bank target?" by G. Mankiw and R. Reis, August 2002.

17I "An estimated stochastic dynamic general equilibrium model of the euro area" by F. Smets and R. Wouters, August 2002.

172 "Constructing quality-adjusted price indices: a comparison of hedonic and discrete choice models" by N. Jonker, September 2002.

173 "Openness and equilibrium determinacy under interest rate rules" by F. de Fiore and Z. Liu, September 2002.

174 "International monetary policy co-ordination and financial market integration" by A. Sutherland, September 2002.

175 "Monetary policy and the financial accelerator in a monetary union" by S. Gilchrist, J.O. Hairault and H. Kempf, September 2002.

176 "Macroeconomics of international price discrimination" by G. Corsetti and L. Dedola, September 2002.

177 "A theory of the currency denomination of international trade" by P. Bacchetta and E. van Wincoop, September 2002.

178 "Inflation persistence and optimal monetary policy in the euro area" by P. Benigno and J.D. López-Salido, September 2002.

179 "Optimal monetary policy with durable and non-durable goods" by C.J. Erceg and A.T. Levin, September 2002.

180 "Regional inflation in a currency union: fiscal policy versus fundamentals" by M. Duarte and A.L. Wolman, September 2002.

18I "Inflation dynamics and international linkages: a model of the United States, the euro area and Japan” by G. Coenen and V. Wieland, September 2002.

182 "The information content of real-time output gap estimates: an application to the euro area” by G. Rünstler, September 2002. 
183 "Monetary policy in a world with different financial systems" by E. Faia, October 2002.

184 "Efficient pricing of large-value interbank payment systems" by C. Holthausen and J.-C. Rochet, October 2002.

185 "European integration: what lessons for other regions? The case of Latin America" by E. Dorrucci, S. Firpo, M. Fratzscher and F. P. Mongelli, October 2002.

186 "Using money market rates to assess the alternatives of fixed versus variable rate tenders: the lesson from 1989-98 data for Germany” by M. Manna, October 2002.

187 “A fiscal theory of sovereign risk” by M. Uribe, October 2002.

188 "Should central banks really be flexible?" by H. P. Grüner, October 2002.

189 "Debt reduction and automatic stabilisation" by P. Hiebert, J. J. Pérez and M. Rostagno, October 2002.

190 "Monetary policy and the zero bound to interest rates: a review" by T. Yates, October 2002.

191 "The fiscal costs of financial instability revisited" by L. Schuknecht and F. Eschenbach, November 2002.

192 "Is the European Central Bank (and the United States Federal Reserve) predictable?" by G. Perez-Quiros and J. Sicilia, November 2002.

193 "Sustainability of public finances and automatic stabilisation under a rule of budgetary discipline" by J. Martn, November 2002.

194 "Sensitivity analysis of volatility: a new tool for risk management" by S. Manganelli, V. Ceci and W. Vecchiato, November 2002.

195 "In-sample or out-of-sample tests of predictability: which one should we use?" by A. Inoue and L. Kilian, November 2002.

196 "Bootstrapping autoregressions with conditional heteroskedasticity of unknown form" by S. Gonoalves and L. Kilian, November 2002.

197 "A model of the Eurosystem's operational framework for monetary policy implementation" by C. Ewerhart, November 2002.

198 "Extracting risk-neutral probability densities by fitting implied volatility smiles: some methodological points and an application to the 3M EURIBOR futures option prices" by A. B. Andersen and T. Wagener, December 2002.

199 "Time variation in the tail behaviour of bund futures returns" by T. Werner and C. Upper, December 2002. 
200 "Interdependence between the euro area and the United States: what role for EMU?" by M. Ehrmann and M. Fratzscher, December 2002.

201 "Euro area inflation persistence" by N. Batini, December 2002.

202 "Aggregate loans to the euro area private sector" by A. Calza, M. Manrique and J. Sousa, January 2003.

203 "Myopic loss aversion, disappointment aversion and the equity premium puzzle" by D. Fielding and L. Stracca, January 2003.

204 "Asymmetric dynamics in the correlations of global equity and bond returns" by L. Cappiello, R.F. Engle and K. Sheppard, January 2003.

205 "Real exchange rate in an inter-temporal n-country-model with incomplete markets" by B. Mercereau, January 2003.

206 "Empirical estimates of reaction functions for the euro area" by D. Gerdesmeier and B. Roffia, January 2003.

207 "A comprehensive model on the euro overnight rate" by F. R. Würtz, January 2003.

208 "Do demographic changes affect risk premiums? Evidence from international data" by A. Ang and A. Maddaloni, January 2003.

209 "A framework for collateral risk control determination" by D. Cossin, Z. Huang, D. Aunon-Nerin and F. González, January 2003.

210 "Anticipated Ramsey reforms and the uniform taxation principle: the role of international financial markets" by S. Schmitt-Grohé and M. Uribe, January 2003.

211 "Self-control and savings" by P. Michel and J.P. Vidal, January 2003.

212 "Modelling the implied probability of stock market movements" by E. Glatzer and M. Scheicher, January 2003.

213 "Aggregation and euro area Phillips curves" by S. Fabiani and J. Morgan, February 2003.

$2 / 4$ "On the selection of forecasting models" by A. Inoue and L. Kilian, February 2003.

215 "Budget institutions and fiscal performance in Central and Eastern European countries" by H. Gleich, February 2003.

216 "The admission of accession countries to an enlarged monetary union: a tentative assessment" by M. Ca'Zorzi and R. A. De Santis, February 2003.

217 "The role of product market regulations in the process of structural change" by J. Messina, March 2003.

218 "The zero-interest-rate bound and the role of the exchange rate for monetary policy in Japan" by G. Coenen and V. Wieland, March 2003. 
219 "Extra-euro area manufacturing import prices and exchange rate pass-through" by B. Anderton, March 2003.

220 "The allocation of competencies in an international union: a positive analysis" by M. Ruta, April 2003.

221 "Estimating risk premia in money market rates" by A. Durré, S. Evjen and R. Pilegaard, April 2003.

222 "Inflation dynamics and subjective expectations in the United States" by K. Adam and M. Padula, April 2003.

223 "Optimal monetary policy with imperfect common knowledge" by K. Adam, April 2003.

224 "The rise of the yen vis-à-vis the ("synthetic") euro: is it supported by economic fundamentals?" by C. Osbat, R. Rüffer and B. Schnatz, April 2003.

225 "Productivity and the ("synthetic") euro-dollar exchange rate" by C. Osbat, F. Vijselaar and B. Schnatz, April 2003.

226 "The central banker as a risk manager: quantifying and forecasting inflation risks" by L. Kilian and S. Manganelli, April 2003.

227 "Monetary policy in a low pass-through environment" by T. Monacelli, April 2003. 